\title{
AGRP Neurons Project to the Medial Preoptic Area and Modulate Maternal Nest-Building
}

\author{
Xing-Yu Li, ${ }^{1,2 *}$ Ying Han, ${ }^{1,2 *}$ (W) Wen Zhang, ${ }^{1 \star}$ Shao-Ran Wang, ${ }^{1,2}$ Yi-Chao Wei, ${ }^{1,2}$ Shuai-Shuai Li, ${ }^{1,2}$ Jun-Kai Lin, ${ }^{1,2}$ \\ Jing-Jing Yan, ${ }^{1,2}$ Ai-Xiao Chen, ${ }^{1,2}$ Xin Zhang, ${ }^{1}$ Zheng-Dong Zhao, ${ }^{3}{ }^{\odot W e i ~ L . ~ S h e n, ~}{ }^{3}$ and ${ }^{\odot X i a o-H o n g ~ X u}{ }^{1}$ \\ ${ }^{1}$ Institute of Neuroscience, State Key Laboratory of Neuroscience, CAS Center for Excellence in Brain Science and Intelligence Technology, Chinese \\ Academy of Sciences, Shanghai 200031, China, ${ }^{2}$ University of the Chinese Academy of Sciences, Beijing 100049, China, and ${ }^{3}$ School of Life Science and \\ Technology, The ShanghaiTech University, Shanghai, 201210, China
}

AGRP (agouti-related neuropeptide) expressing inhibitory neurons sense caloric needs of an animal to coordinate homeostatic feeding. Recent evidence suggests that AGRP neurons also suppress competing actions and motivations to mediate adaptive behavioral selection during starvation. Here, in adult mice of both sexes we show that AGRP neurons form inhibitory synapses onto $\sim 30 \%$ neurons in the medial preoptic area (mPOA), a region critical for maternal care. Remarkably, optogenetically stimulating AGRP neurons decreases maternal nest-building while minimally affecting pup retrieval, partly recapitulating suppression of maternal behaviors during food restriction. In parallel, optogenetically stimulating AGRP projections to the mPOA or to the paraventricular nucleus of hypothalamus but not to the LHA (lateral hypothalamus area) similarly decreases maternal nest-building. Chemogenetic inhibition of mPOA neurons that express Vgat (vesicular GABA transporter), the population targeted by AGRP terminals, also decreases maternal nest-building. In comparison, chemogenetic inhibition of neurons in the LHA that express vesicular glutamate transporter 2, another hypothalamic neuronal population critical for feeding and innate drives, is ineffective. Importantly, nest-building during low temperature thermal challenge is not affected by optogenetic stimulation of AGRP $\rightarrow$ mPOA projections. Finally, via optogenetic activation and inhibition we show that distinctive subsets of mPOA Vgat + neurons likely underlie pup retrieval and maternal nest-building. Together, these results show that AGRP neurons can modulate maternal nest-building, in part through direct projections to the $\mathrm{mPOA}$. This study corroborates other recent discoveries and underscores the broad functions that AGRP neurons play in antagonizing rivalry motivations to modulate behavioral outputs during hunger.

Key words: AGRP; behavioral antagonism; hunger; maternal nest-building; medial preoptic area; neural circuit

Significance Statement

In order for animals to initiate ethologically appropriate behaviors, they must typically decide between behavioral repertoires driven by multiple and often conflicting internal states. How neural pathways underlying individual behaviors interact to coherently modulate behavioral outputs, in particular to achieve a proper balance between behaviors that serve immediate individual needs versus those that benefit the propagation of the species, remains poorly understood. Here, by investigating projections from a neuronal population known to drive hunger behaviors to a brain region critical for maternal care, we show that activation of AGRP $\rightarrow$ mPOA projections in females dramatically inhibits maternal nest-building while leaving mostly intact pup retrieval behavior. Our findings shed new light on neural organization of behaviors and neural mechanisms that coordinate behavioral selection.

\section{Introduction}

AGRP-expressing neurons $(\sim 20,000)$ in the arcuate nucleus (ARC) of the hypothalamus sense caloric needs of an animal to

Received April 12, 2018; revised Nov. 6, 2018; accepted Nov. 11, 2018.

Author contributions: X.-H.X. wrote the first draft of the paper; X.-H.X. edited the paper; X.-Y.L., Y.H., W.Z., S.-R.W., and X.-H.X. designed research; X.-Y.L., Y.H., W.Z., S.-R.W., Y.-C.W., S.-S.L., J.-K.L., X.Z., and Z.-D.Z. performed research; Y.-C.W. and W.L.S. contributed unpublished reagents/analytic tools; X.-Y.L., Y.H., W.Z., S.-R.W., Y.-C.W., S.-S.L., J.-K.L., J.-J.Y., A.-X.C., Z.-D.Z., and X.-H.X. analyzed data; X.-H.X. wrote the paper.

This work is supported by Grants from the National Nature Science Foundation of China [31471065 (X.-H.X.), 31871066 (X.-H.X.), 31771169 (W.L.S.)], Ministry of Science and Technology Office China 973 program(2015CB559201 to X.-H.X.), the Thousand Young Talents Program of China, the Strategic Priority Research Program of the Chinese Academy of Sciences (XDB02030005 and XDBS01010200 to X.-H.X.), and as part of the CAS coordinate homeostatic feeding (Zha and Xu, 2015; Andermann and Lowell, 2017). These neurons are activated by hormones that signal caloric deficiency, such as ghrelin (Hahn et al., 1998; Kamegai et al., 2000; Cowley et al., 2003; Palou et al., 2009), and

interdisciplinary innovation team. We thank members of the Xu Laboratory for comments on the paper, and Drs. Ju Huang, Yan-Gang Sun, and Hua-Tai Xu for assistance with animals.

The authors declare no competing financial interests.

${ }^{*}$ X.-Y.L., Y.H., and W.Z. contributed equally to this work.

Correspondence should be addressed to Dr. Xiao-Hong Xu, Chinese Academy of Sciences, 320 Yueyang Road Biological Experiment Building A805, Shanghai 200031, China. E-mail: xiaohong.xu@ion.ac.cn.

https://doi.org/10.1523/JNEUROSCI.0958-18.2018

Copyright $\odot 2019$ the authors $\quad 0270-6474 / 19 / 390456-16 \$ 15.00 / 0$ 
suppressed by hormones that signal energy surfeit, such as leptin (Cowley et al., 2001; Pinto et al., 2004; Varela and Horvath, 2012). In addition, sensory cues that predict food availability rapidly suppress AGRP neuronal activities, whereas gut-derived nutrients and hormones post-ingestion suppress AGRP neuronal activities over minutes to hours (Betley et al., 2015; Chen et al., 2015; Mandelblat-Cerf et al., 2015; Beutler et al., 2017; Su et al., 2017). Functionally, optogenetic or chemogenetic activation of AGRP neurons drives food foraging and voracious feeding even in satiated animals (Aponte et al., 2011; Krashes et al., 2011). Conversely, targeted suppression or ablation of AGRP neurons leads to reduced or dramatic loss of feeding in adult mice (Luquet et al., 2005, Krashes et al., 2011; Betley et al., 2015). Thus, AGRP neurons play an absolutely essential role in maintaining homeostatic feeding.

AGRP neurons project prominently to the paraventricular nucleus of hypothalamus (PVH), the dorsal medial hypothalamus (DMH), the lateral hypothalamic area (LHA), the anterior bed nucleus of the stria terminalis (aBNST), the paraventricular nucleus of the thalamus (PVT), the central amygdala (CeA), and the parabrachial nucleus (PBN), where they release GABA along with AGRP and neuropeptide Y to exert inhibitory effects on downstream neurons (Wu et al., 2009, 2012; Atasoy et al., 2012; Betley et al., 2013; Carter et al., 2013; Krashes et al., 2013). Interestingly, each of these target regions receives inputs from a separate and non-overlapping subset of AGRP neurons (Betley et al., 2013). Independent activation of AGRP projections to PVH, LHA, aBNST, and PVT but not to CeA or PBN elicits feeding, suggesting a parallel and redundant configuration of AGRP neural pathways for homeostatic feeding (Betley et al., 2013).

Importantly, hunger as an internal state broadly influences perception and behaviors beyond feeding. Indeed, recent studies show that AGRP neurons could act via projections to the PVT and to the basolateral amygdala to modulate representation of food-predicting visual cues in the insular cortex (Livneh et al., 2017), via projections to the medial nucleus of the amygdala to suppress territorial aggression and contextual fear (Padilla et al., 2016), via projections to the PBN to attenuate behavioral responses and affective properties of inflammatory pain induced by formalin injection (Alhadeff et al., 2018), and via inhibition of kisspeptin-expressing neurons to suppress fertility (Padilla et al., 2017). Moreover, when food is accessible, activation of AGRP neurons also mediate hunger suppression of other behaviors and motivations, including thirst, anxiety-related behavior, innate fear, and social interactions (Burnett et al., 2016; Jikomes et al., 2016). These results raise the question as to whether AGRP neurons may play a similar role in antagonizing maternal care, the balance between which and feeding could potentially affect the fitness of an animal.

In this study, by performing ex vivo channelrhodopsin-2assisted circuit mapping (Petreanu et al., 2007), we demonstrate a direct projection from AGRP neurons to $~ 30 \%$ neurons in the medial preoptic area (mPOA), a region essential for maternal care (Numan, 1974; Jacobson et al., 1980; Newman, 1999; Tsuneoka et al., 2013; Dulac et al., 2014; Kuroda and Numan, 2014; Wu et al., 2014; Yang and Shah, 2014). Optogenetic stimulation of AGRP neurons or their projections to the mPOA or chemogenetic inhibition of $\mathrm{mPOA}$ vesicular GABA transporter (Vgat) + neurons, the population targeted by AGRP neurons, dramatically decreases maternal nest-building while minimally affecting pup retrieval, partly recapitulating suppression of maternal behaviors in starved females. By contrast, nest-building behavior induced by thermal challenge is not affected by stimu- lation of $\mathrm{AGRP} \rightarrow \mathrm{mPOA}$ projections. Together, these results show that AGRP $\rightarrow$ mPOA projections can directly modulate maternal nest-building.

\section{Materials and Methods}

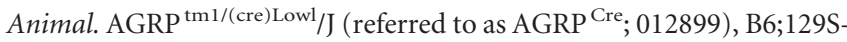

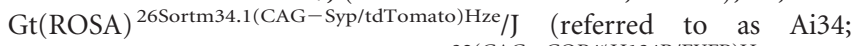
012570), B6;129S-Gt(ROSA)26Sor ${ }^{\mathrm{tm} 32\left(\mathrm{CAG}-\mathrm{COP}^{\star}{ }^{*} \mathrm{H} 134 \mathrm{R} / \mathrm{EYFP}\right) \mathrm{Hze}} / \mathrm{J}$ (referred to as Ai32; 012569), Slc32a ${ }^{\mathrm{tm} 2(\mathrm{cre}) / \text { Lowl } / J}$ (referred to as Vgat-Ires-

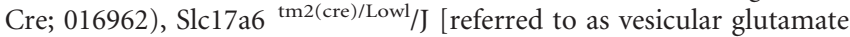
transporter 2 (Vglut2)-Ires-Cre; 01693], and C57BL/6-Esr1tm ${ }^{2.1(\text { cre)And/J }}$ (referred to as Esr1-Cre; 017913) were obtained from The Jackson Laboratory. Vgat-Cre was previously generated (Chao et al., 2010). C57BL/6 animals were obtained from the Slac Laboratory Animal. All experimental animals used in the study were $>8$ weeks old and were bred onto $\mathrm{C} 57 \mathrm{BL} / 6$ background for at least one generation. Animals were housed in the Institute of Neuroscience animal facility on a $12 \mathrm{~h}$ light/dark cycle and with food and water ad libitum unless otherwise specified. Animals heterozygous for the AGRP ${ }^{\text {cre }}$ and Ai34 allele were used to trace target areas of AGRP neurons. Animals heterozygous for the AGRP ${ }^{\text {cre }}$ and Ai32 allele, denoted as AGRP ${ }^{\mathrm{ChR} 2}$ mice, were used for functional manipulations. All experimental protocols were approved by the Animal Care and Use Committee (IACUC No. NA-016-2016).

Electrophysiological recordings. Adult AGRP ${ }^{\mathrm{ChR} 2}$ mice of either sex were anesthetized with isoflurane, perfused transcardially with ice-cold oxygenated $\left(95 \% \mathrm{O}_{2} / 5 \% \mathrm{CO}_{2}\right.$ ) high-sucrose solution (in mM: $2.5 \mathrm{KCl}$, $1.25 \mathrm{NaH}_{2} \mathrm{PO}_{4}, 2 \mathrm{Na}_{2} \mathrm{HPO}_{4}, 2 \mathrm{MgSO}_{4}, 213$ sucrose, $26 \mathrm{NaHCO}_{3}$ ), and decapitated to remove the brain. Afterward, the brain was immediately placed in ice-cold oxygenated high-sucrose solution and sectioned in coronal plane at $250 \mu \mathrm{m}$ in this buffer. After sectioning, slices were incubated in oxygenated ACSF (in mM: $126 \mathrm{NaCl}, 2.5 \mathrm{KCl}, 1.25$ $\mathrm{NaH}_{2} \mathrm{PO}_{4}, 1.25 \mathrm{Na}_{2} \mathrm{HPO}_{4}, 2 \mathrm{MgSO}_{4}, 10$ glucose, $26 \mathrm{NaHCO}_{3}, 2 \mathrm{CaCl}_{2}$ ) at $34^{\circ} \mathrm{C}$ for $1 \mathrm{~h}$. The intracellular solution for action potential recording containing the following (in $\mathrm{mM}$ ): $120 \mathrm{~K}$-gluconate, $4 \mathrm{KCl}, 10 \mathrm{HEPES}, 10$ sodium phosphocreatine, $4 \mathrm{Mg}$-ATP, and 0.3 $\mathrm{Na}_{3}$-GTP, pH 7.3, 265 mOsm. Clozapine- $N$-oxide $(\mathrm{CNO} ; 5 \mu \mathrm{M})$ was bath applied on the slices for 5 min during recordings of neurons that expressed HM4D, which were identified by the expression of mCherry. The intracellular solution for voltage-clamp IPSCs recording contained the following (in $\mathrm{mm}$ ): $125 \mathrm{CsCl}, 5 \mathrm{MgCl}_{2}$, 0.6 EGTA, $10 \mathrm{HEPES}, 10$ lidocaine hydrochloride (QX-314), 4 Mg-ATP, and $0.3 \mathrm{Na}_{3}$-GTP, pH 7.3, $280 \mathrm{mOsm}$. Photostimulation-evoked (pulse duration $10 \mathrm{~ms}, 7 \mathrm{~mW} / \mathrm{mm}^{2}$ ) IPSCs were recorded with membrane potential holding at $-70 \mathrm{mV}$ in the presence of CNQX (10 $\mu \mathrm{M}$; Tocris Bioscience) and DL-AP5 (50 $\mu \mathrm{M}$; Sigma). Blue light was delivered through $40 \times$ objective on a fluorescence microscope BX51 (Olympus) with X-Cite LED light source. All recordings were acquired using MultiClamp 700B amplifier and Digidata 1440A interface (Molecular Devices). Directly after IPSC recordings, the contents of the recorded neurons in females were aspirated into the patch electrode. The electrode tip was then broken off to release the content into a thin-wall PCR tube containing $50 \mu \mathrm{m}$ random hexamers and $10 \mathrm{~mm}$ dNTP mix. PCR tubes were immediately frozen in liquid nitrogen until use.

Single-cell RT-PCR. Single-cell reverse transcription (RT)-PCR analysis of recorded cells was performed using a similar protocol as described previously (Pfeffer et al., 2013). Briefly, the cDNA library of the recorded cells was generated using random hexamers and the SuperScript IV kit (Invitrogen, 18091050) according to the manufacturer's protocol. Internal solution was transcribed along as a negative control. Afterward, multiplex PCR was performed with $2 \times$ TaqPCR MasterMix (Tiangen, KT201-02) using primers for three targeted genes in a volume of $25 \mu \mathrm{l}$. Multiplex primers were designed to amplify exonic DNA sequences and spanned at least one exon-intron boundary. Water control experiments were regularly performed to detect contamination. Next, nested single gene PCR was performed in a volume of $25 \mu \mathrm{l}$ with a 1:25 dilution of the multiplex PCR products using the standard $2 \times$ TaqPCR MasterMix (Tiangen, KT201-02). Nested primers were designed to amplify 100-400 bp DNA sequences within the boundary of the multiplex PCR primers. PCR products were visualized using standard agarose gel electrophoresis 
and visualized/documented under the UV light. All primers used were first tested with dilutions of mPOA cDNA libraries for sensitivity and specificity. The following primers are used in this study: Vgat (137 bp) 5'-GTCACGACAAACCCAAGATCAC-3', 5'-GGCGAAGATGATGAG GAACAAC-3'; Vglut2 (891 bp) 5'-AGGGTTCGATGACGTTTCTGG3', 5'-AGCGGATGCCGAAGGATATG-3'; (313 bp) 5' -CTATTAGGA AACCCGTGGGCTG-3', 5'-CTTCTTCTCCAGCACCCTGTA-3'; GAPDH, (500 bp) 5' -ACCACAGTCCATGCCATCAC-3', 5' -GGGTGGTCCAGG GTTTCTTA-3'; (138 bp) 5'-TCCACCACCCTGTTGCTGTA-3', 5' GGTTGTCTCCTGCGACTTCA-3'. Note that the multiplex and nested primers for Vgat were the same and were adopted from Padilla et al. (2016), whereas the rest of the primers were custom designed using NCBI primer-blast.

Stereotactic surgery. Stereotactic surgeries were performed generally on a David Kopf 1900 stereotactic frame with female animals anesthetized under isoflurane. Surgeries to implant optic fibers into the LHA were performed on a RWD stereotactic frame (model 68507, RWD Life Science) with pentobarbital $(120 \mathrm{mg} / \mathrm{kg})$ used as the anesthesia. Briefly, the skull was exposed with a small incision and holes were drilled to implant optic fibers or to deliver virus with glass pipettes (15-25 $\mu \mathrm{m}$ diameter at the tip). Unilateral optic fibers ( $200 \mu \mathrm{m}$ diameter, N.A. $=0.37$, length 7 $\mathrm{mm}$, AniLab Software and Instruments) or bilateral optic fibers (DFC_200/245-0.37_6.0 mm_DF0.85_FLT, Doric Lenses) were inserted through the drilled holes and secured onto the skull with dental cement and screws. The coordinates to implant optic fibers were as follows (in $\mathrm{mm})$ : ARC, bregma: AP: -1.700 , ML: -0.250 , DV: -5.650 ; PVH, bregma: AP: -0.82 , ML: -0.00 , DV: -4.30 ; mPOA, bregma: AP: +0.120 , ML: $\pm 0.450, \mathrm{DV}:-4.700$. Two unilateral fibers were implanted at an angle of $10^{\circ}$ with the tips of the optic fibers placed $400 \mu \mathrm{m}$ over the LHA for each hemisphere at the coordinates of bregma (in mm): AP: -1.300 , ML: $\pm 1.000, D V: 4.600$. Optic fiber implanted animals were allowed at least 1 week to recover before behavioral tests. For viral injections, the coordinates of bregma (in mm): AP: +0.160 , DV: -5.100 , ML: \pm 0.400 were used to target the mPOA bilaterally; the coordinates of bregma (in $\mathrm{mm})$ : AP: -1.1 , DV: -5.100 , ML: \pm 1.125 were used to target the LHA. Injections of 200-300 nl virus per side were made with a hydraulic pump at a speed of $40 \mathrm{nl}$ per minute. Viral-injected animals were allowed at least 3 weeks after the surgery to recover and to express the virus before subsequent behavioral tests. Viruses used in the study include AAV-hSynDIO-HM4D-mCherry (titer $7 \times 10 \mathrm{e} 12$ genomic copies/ml, UNC Vector Core, Serotype 2/8), AAV-EF1a-DIO-mCherry (titer $8.93 \times 10 \mathrm{e} 12$ genomic copies/ml, Obio Technology, Serotype 2/8), AAV-EF1a-DIOChR2-mCherry (titer $7.39 \times 10 \mathrm{e} 12$ genomic copies/ml, Obio Technology, Serotype 2/8), AAVs-CAG-DIO-GtACR1-P2A-EGFP (titer $7.5 \times$ 10e12 genomic copies/ml, Shanghai Taitool Bioscience, Serotype 2/5), AAVs-Ef1a-DIO-EYFP (titer $8.6 \times 10 \mathrm{e} 12$ genomic copies/ml, Shanghai Taitool Bioscience, Serotype 2/9).

Behavioral test. Female animals were singly housed for at least $3 \mathrm{~d}$ before the behavioral tests except when they were tested as mothers, in which case they were tested in their own cage. Maternal behaviors were tested by scattering three pups ages $\mathrm{P} 1-\mathrm{P} 4$ at the edge away from the nest and videotaping the animal for 15-30 min. Videotapes (15 min) were scored by an experimenter blind to the treatment of the animal using a custom written MATLAB program as previously described (Xu et al., 2012). Pup retrieval behavior was scored when the animal picked up the pups and moved it toward the nest site. A retrieval score of "1" was given to each pup successfully moved to the nest site, " 0 " if not retrieved at all. If a pup was retrieved but not to the nest, a number between 0.1 and 0.9 , varying according to the final distance of a pup to the nest at the end of an assay, was given, similar to previously described (Scott et al., 2015). Nestbuilding was scored when the animals actively collected and arranged the nest material in a stereotyped motion. Nest quality was scored using a scale system based on the scatterings of the material and the shape of the nest: 0 , all nest material remaining scattered; $1,<50 \%$ of the material gathered; $2,50-80 \%$ of the material gathered; $3,>80 \%$ but not all of the material gathered; 4, all materials gathered but the nest is flat; 5 , all materials gathered but the nest is not oval; and 6 , nest is a crater with walls higher than the height of the mouse.
For food deprivation (FD) experiment, females were moved to a fresh cage without food but with water for $\sim 25 \mathrm{~h}$. Afterward, pups were introduced and behaviors videotaped. FD experiments were performed at least $5 \mathrm{~d}$ apart. For optogenetic stimulation experiments done in female AGRP ${ }^{\text {ChR2 }}$ animals, an external optic fiber $(\sim 0.65-1 \mathrm{~m}$ long $)$ was used to connect a $473 \mathrm{~nm}$ laser power source (Changchun New Industries Optoelectronics Tech) to the implanted optic fiber in the animal. The external optic fiber was attached to a rotary joint (FRJ_1X1_FC_FC, Doric Lens) to allow the animal to move freely. The laser was controlled by a Master- 8 to deliver $20 \mathrm{~Hz}$ light pulse ( $10 \mathrm{~ms}$ width) at a pattern of $1 \mathrm{~s}$ on and $3 \mathrm{~s}$ off. Light power was adjusted for each animal according to the luminance transitivity efficiency of the implanted optic fiber to assure that light emitted at the tip of fiber was $7 \mathrm{~mW}$. All optical stimulation experiments were performed at least $1 \mathrm{~h}$ after the onset of the light cycle. On the day of testing, the external optic fiber was attached to the animal at the beginning of the adaption period whether or not light would be delivered in the trial. In light-stimulated trials, light was delivered $10 \mathrm{~min}$ before the introduction of pups and throughout the test. Each animal was tested for three trials each day of alternating light/no light trial with half an hour of rest in between trials and was tested for 2 consecutive days. All lactating females were previously tested as virgins. In light-stimulated trials, pups were temporally removed and light was delivered $10 \mathrm{~min}$ before the introduction of pups back to the cage and continued during the behavioral assay. To test the effects of activation of AGRP $\rightarrow \mathrm{mPOA}$ terminals on nest-building behavior during thermal challenge, the room temperature was change to $16^{\circ} \mathrm{C}$, an external optic fiber was attached to the female animal and the nest material was scattered. In light trial, a stimulation pattern of a $1.5 \mathrm{~h}$ light on period followed by a $1.5 \mathrm{~h}$ light off period and another $1.5 \mathrm{~h}$ light on period was given. In no light trial, animals were recorded with external fiber attached but no light delivered for a total of $4.5 \mathrm{~h}$. Animals were allowed for at least $5 \mathrm{~d}$ rest in between trials and each animal was tested only once for either light or no-light condition. To chemogenetically inhibit mPOA Vgat + or LHA Vglut2+ neurons, either saline or CNO $(\sim 1 \mathrm{mg} / \mathrm{kg}$, Enzo $)$ were administrated intraperitoneally $1-2 \mathrm{~h}$ before the maternal behavioral tests, which were performed at least half an hour after the onset of dark cycle and at most once per day, or $1-2 \mathrm{~h}$ before the feeding test, which was performed after the onset of light cycle. Each female animal was tested once or twice with saline or CNO injection for each behavioral test. Optogenetic activation and inhibition of the mPOA Vgat+ or Esr1+ neurons in females were performed as previously described (Wei et al., 2018). Briefly, optogenetic activation was performed in virgin females and animals were tested in fresh cages either in presence of scattered pups or scattered nesting materials. Phasic light ( $473 \mathrm{~nm}, 15 \mathrm{~s}, 12 \mathrm{~mW}, 40 \mathrm{~Hz}, 10 \mathrm{~ms}$ pulse) was randomly delivered $90-120 \mathrm{~s}$ apart. For optogenetic inhibition of the $\mathrm{mPOA}$, female animals were mated after viral injection to produce their own pups and were housed with the pups and tested for behaviors during lactation or postpartum after weaning of pups. To inhibit during pup approaching, light ( $\sim 12 \mathrm{~mW}, 473 \mathrm{~nm}$ ) was automatically triggered to be continuously delivered as long as the position of the tested animal was detected by the program to be within the pup region, which was defined by marking a slight larger area surrounding each scattered pup. To inhibit after initiation of defined behaviors, blue light $(\sim 12 \mathrm{~mW}, 473 \mathrm{~nm})$ of fixed length $(5 \mathrm{~s})$ was manually triggered when the experimenter observed the behavior of interests in real-time. One or two light or no-light trials were performed.

All animals were killed upon completion of all behavioral experiments and processed to analyze fiber placements or viral infection. Upon post hoc histological and behavioral analysis, data points from animals that were deemed mis-hits or displayed poor baseline maternal behaviors were excluded. Specifically, 9 of 36 AGRP $^{\text {ChR2 }}$ females implanted with optic fibers in the arcuate nucleus were excluded for mis-placed fibers; 3 of 21 AGRP $^{\text {ChR2 }}$ females implanted with bilateral optic fibers in the mPOA were excluded for mis-placed fibers; 1 of 9 AGRP ${ }^{\text {ChR2 }}$ females implanted with an optic fiber in the PVH was excluded for mis-placed fiber; 3 of 10 AGRP ${ }^{\mathrm{ChR} 2}$ females implanted with bilateral optic fibers in the LHA were excluded for displaying no maternal nest-building under no-light condition (and under light condition); 5 of 17 mPOA HM4D female animals were excluded for unilateral viral expression; 5 of 16 LHA 
HM4D female animals were excluded for viral expression in other brain areas including DMH, ventral medial hypothalamic nucleus and PVH; 1 of 9 GtACR1 female animals were excluded for mis-targeted expression of the virus.

Histological analysis. For immunohistochemistry, mice were transcardially perfused with PBS followed by $4 \%$ paraformaldehyde (PFA) in PB. Brain was postfixed overnight at $4^{\circ} \mathrm{C}$ and sectioned at $40 \mu \mathrm{m}$ using vibratome (Leica). Brain sections were blocked in 5\% goat serum in AT $\left(0.1 \%\right.$ Triton and $2 \mathrm{mM} \mathrm{MgCl}_{2}$ in PBS) for $1 \mathrm{~h}$ at room temperature and incubated overnight at $4^{\circ} \mathrm{C}$ in AGT $(0.5 \%$ goat serum, $0.1 \%$ Triton, and $2 \mathrm{mM} \mathrm{MgCl}_{2}$ in PBS) containing appropriate primary antibody (rabbit anti-c-Fos, 1:1000, Santa Cruz Biotechnology, catalog \#sc-52; chicken anti-GFP, 1:500, Abcam, catalog \#ab13970; rabbit anti-GFP, 1:1000, Invitrogen, catalog \#A11122). The next day, sections were washed in AGT and incubated with appropriate secondary antibody for $2 \mathrm{~h}$ at room temperature. After three washes in AGT, NeuroTrace 435/455 (Life Technologies, catalog \#N21479; 1:300) was diluted in AT solution and incubated with the sections for $20 \mathrm{~min}$ as a counter staining. After staining, slides were washed in AT and fixed in 4\% PFA for $20 \mathrm{~min}$. After washes in PBS, sections were mounted onto slides. To analyze the infection rate of the virus, mCherry or GFP signal was visualized and counted and divided by the total number of Nissl+ cells in the infected region. AGRP terminals were visualized on a confocal microscope using a $20 \times$ objective. To analyze and compare density of AGRP neurons in different brain regions, images were captured under a $20 \times$ objective on a regular microscope. For each brain region, three $130 \times 130 \mu \mathrm{m}$ squares were picked per brain region and the mean gray value was measured in ImageJ for each square and were averaged to get the value of mean intensity.

Experimental design and statistical analysis. Littermates of the same genotype were randomly assigned to be either the control or the experiment group. At least two batches of animals were carried for each experiment and the results from different batches were combined. All behavioral trials were performed in a balanced manner. Values are presented as mean \pm SEM. For comparison of two groups, if the data were tested to be Gaussian distribution with Shaprio-Wilk normality test and the variances were tested to be equal with $F$ test in GraphPad, $p$ values were calculated with paired or unpaired two-tailed Student's $t$ test according to whether the data are matched or not, whereas $t$ test with Welch's correction was applied to data with Gaussian distribution but unequal variances; otherwise, $p$ values were calculated with Wilcoxon signed rank test for matched pairs and Mann-Whitney $U$ test for nonpair test. When the sample sizes were too small for normality test, which only happened for data in Figure 8, data were assumed to be normally distributed. Categorical data were compared with Fisher's exact test. ${ }^{*} p<0.05,{ }^{* *} p<0.01,{ }^{* * *} p<0.001$.

\section{Results}

\section{AGRP neurons project to the mPOA}

We crossed AGRP ${ }^{\text {Cre }}$ animals with a reporter line (Ai34, MGI: 4947243) that encodes Cre-inducible expression of tdTomato fused with synaptophysin, a synaptic vesicle protein, to fluorescently labels all axon terminals of AGRP neurons (Fig. 1A; Valtorta et al., 2004; Xu and Südhof, 2013). In such a compound line (AGRP $^{\mathrm{Cre}}:$ :Ai34), we detected moderate tdTomato signals in the mPOA in both sexes, as marked by the expression of estrogen receptor $\alpha$ (ER $\alpha$ or Esr1) in this region (Fig. 1B; Wei et al., 2018). This observation is consistent with previous reports of AGRP immunoreactivity, which labels both axon fibers and terminals, in the mPOA (Broberger et al., 1998; Betley et al., 2013). Indeed,

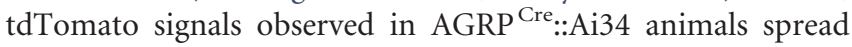
over the entire MPOA and closely match with the pattern of AGRP immunostaining in wild-type mice (Fig. 1C). Moreover, the average mean fluorescent intensity of tdTomato signals detected in the mPOA was slightly lower compared with other well known targets of AGRP neurons, such as the PVH and the LHA (Fig. 1D), suggesting lower projection density.

\section{AGRP neurons form inhibitory synapses onto mPOA neurons}

To confirm that AGRP neurons form functional synapses onto mPOA neurons, we crossed AGRP ${ }^{\text {Cre }}$ animals with a reporter line that encodes Cre-inducible expression of the light-sensitive cation channel channelrhodopsin-2 (ChR2) fused with EYFP (Fig. 2A; Madisen et al., 2012). These animals are referred to here and after as AGRP ${ }^{\mathrm{ChR} 2}$ animals. In these animals, we recorded IPSCs by performing whole-cell patch-clamp in mPOA brain slices while repeatedly delivering a single, blue light pulse (473 nm, 10 ms, 30 sweeps, $4 \mathrm{~s}$ per sweep) to activate AGRP terminals (Fig. $2 B)$. We found that in both male and female $\sim 30 \%$ mPOA neurons recorded ( 14 of 53 cells from 6 females and 18 of 56 cells from 5 males) reliably responded with an IPSC that could be reversibly blocked by $\mathrm{GABA}_{\mathrm{A}}$ receptor antagonist, Bicuculline $(20 \mu \mathrm{M})$ (Fig. 2C). The onset latency, amplitude, and decay time constant of light-evoked IPSCs were comparable between male and female and were on par with AGRP synapses recorded in other brain regions (latency: female $8.73 \pm 0.39 \mathrm{~ms}$, male, $9.89 \pm$ $0.45 \mathrm{~ms}$, unpaired two-tailed $t$ test, $t=1.952, \mathrm{df}=23, p=0.0632$; amplitude: female $124.45 \pm 28.72 \mathrm{pA}$, male, $294.54 \pm 90.72 \mathrm{pA}$, unpaired two-tailed $t$ test, $t=1.726, \mathrm{df}=23, p=0.0977$; decay time constant: female $16.56 \pm 1.67 \mathrm{~ms}$, male, $19.32 \pm 2.2 \mathrm{~ms}$, unpaired two-tailed $t$ test, $t=0.988, \mathrm{df}=23, p=0.334$; Fig. $2 D$; Atasoy et al., 2012).

Moreover, when we delivered trains of light pulses $(473 \mathrm{~nm}$, $10 \mathrm{~ms}, 20 \mathrm{~Hz}, 1 \mathrm{~s}$ on and $3 \mathrm{~s}$ off) to stimulate AGRP terminals, a protocol known to induce a level of AGRP neuronal activation comparable to that after $\sim 24$ h FD (Atasoy et al., 2012; Mandelblat-Cerf et al., 2015; Jikomes et al., 2016), IPSC frequencies in these neurons increased significantly (female, $N=13$; first: $10.99 \pm 1.78 \mathrm{~Hz}$, second(light): $19.05 \pm 2.85 \mathrm{~Hz}$, third: $12.02 \pm$ $1.82 \mathrm{~Hz}$, fourth: $8.39 \pm 1.44 \mathrm{~Hz}$, paired two-tailed $t$ test; first vs second: $t=4.799, \mathrm{df}=12, p=0.0004$, third vs second: $t=3.264$, $\mathrm{df}=12, p=0.0068$, fourth vs second: $t=4.990, \mathrm{df}=12, p=$ 0.0003; Fig. $2 E$; male, $N=15$; first: $5.06 \pm 0.76 \mathrm{~Hz}$, second(light): $7.81 \pm 1.51 \mathrm{~Hz}$, third: $4.81 \pm 0.94 \mathrm{~Hz}$, fourth: $4.19 \pm 0.82 \mathrm{~Hz}$, Wilcoxon matched-pairs signed rank test; first vs second: sum of signed ranks $=66, p=0.0637$, third vs second: sum of signed ranks $=-102, p=0.002$; fourth vs second: sum of signed ranks $=-104, p=0.0015$; Fig. $2 F)$. In particular, 12 of 13 cells in 6 of 6 females and 10 of 15 cells in 3 of 5 males showed increased IPSC frequencies under light. Interestingly, the basal IPSC frequency of these cells is higher in female than male (female: $10.99 \pm 1.78 \mathrm{~Hz}, N=13$, male: $5.06 \pm 0.76 \mathrm{~Hz}, N=15$, unpaired two-tailed $t$ test with Welch's correction, $t=3.059$, $\mathrm{df}=16.28$, $p=0.0074$ ), suggesting more spontaneous activities of inhibitory inputs onto these neurons in female.

\section{Activation of AGRP neurons suppresses maternal nest-building}

Given the demonstrated role of the mPOA in regulating active components of maternal care including pup retrieval and maternal nest-building (Tsuneoka et al., 2013; Wu et al., 2014; Wei et al., 2018), identification of AGRP $\rightarrow$ mPOA projections immediately suggests that hunger may directly modulate maternal care. To test this, we food deprived multiparous females for $\sim 25 \mathrm{~h}$ and tested their behaviors toward scattered pups that were placed away from the nest in a $15 \mathrm{~min}$ behavioral assay. We found that compared with ad libitum condition FD decreased the percentage of animals that successfully retrieved all pups to the nest without affecting the occurrence of pup retrieval (Table 1). Strikingly, FD also strongly suppressed maternal nest-building such that only 1 
A

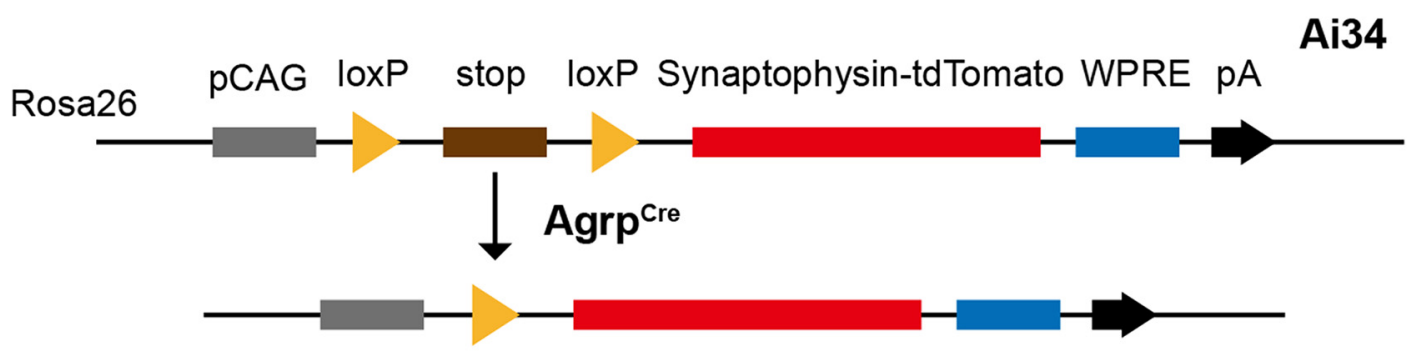

B

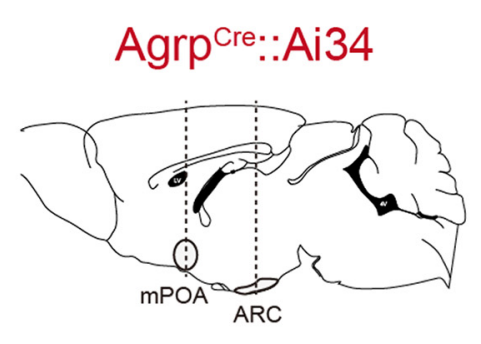

td-Tomato

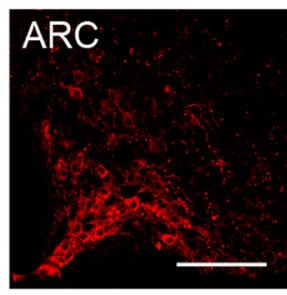

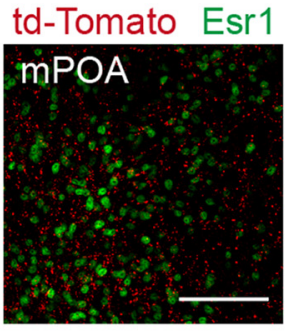

D

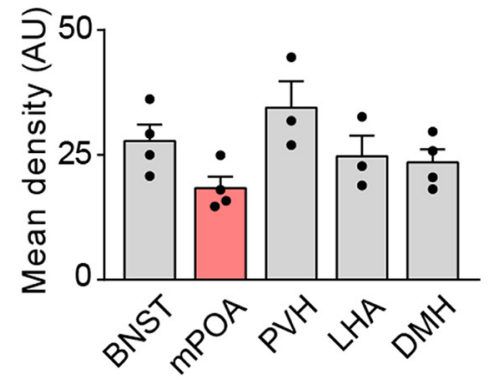

C
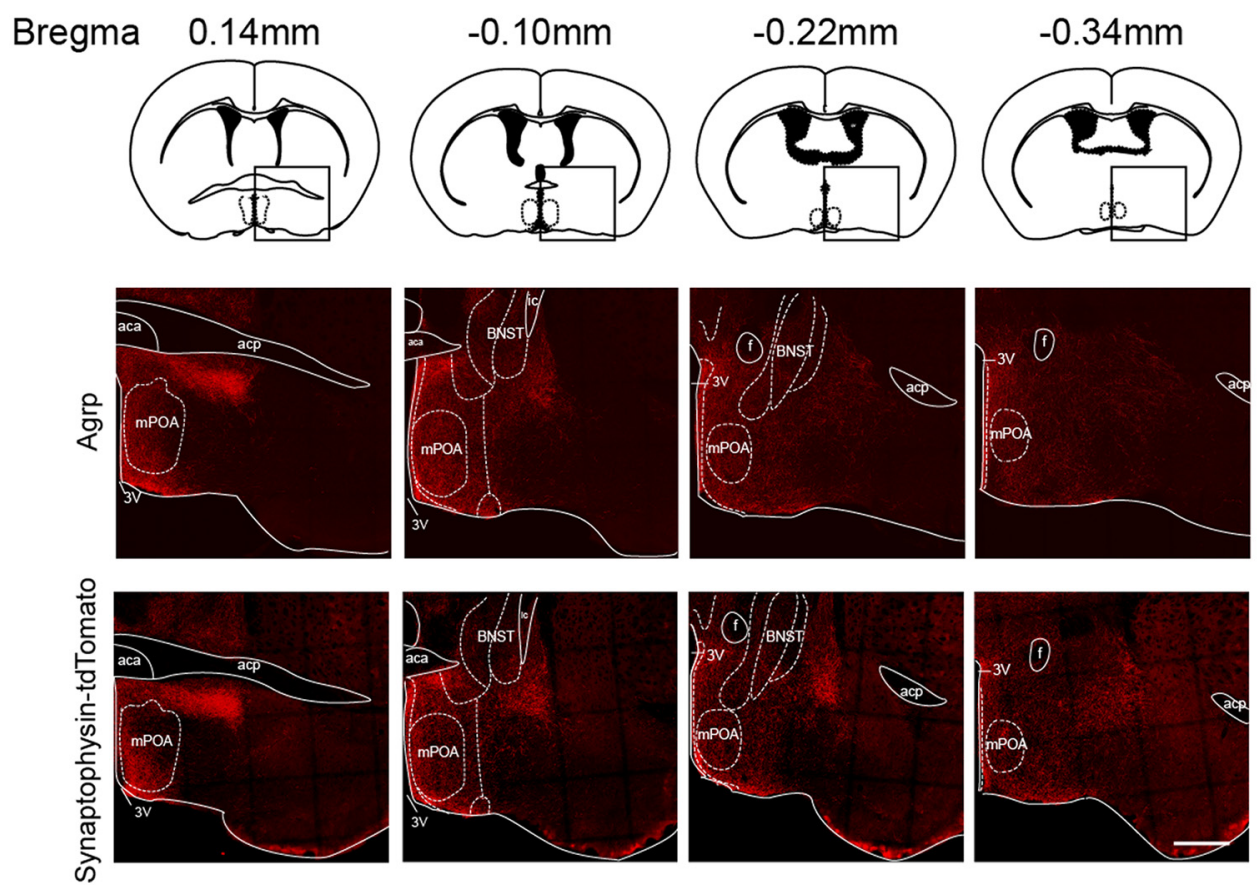

Figure 1. Identification of the MPOA as a downstream target of AGRP neurons. A, Illustration of the genetic strategy to fluorescently label synapses of AGRP neurons. In AGRP cre.::Ai34 animals, Cre induces excision of the stop codon to allow expression of synaptophysin, a synaptic protein, fused with tdTomato in AGRP neurons. B, Representative coronal sections of AGRP cre::Ai34 females showing fluorescent tdTomato signals detected in the ARC and in the $\mathrm{MPOA}$, which was costained with antibodies against Esr 1 . The plane of the sections is indicated by the dashed line in the sagittal section on the left. Scale bar, $100 \mu \mathrm{m}$. C, Representative images showing patterns of AGRP immunostaining in wild-type females (top row) and Synaptophysin-tdTomato signals (bottom row) in

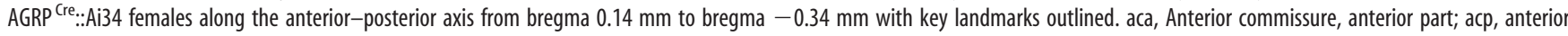
commissure, posterior; ic, internal capsule; $f$, fornix; $3 V$, third ventricle. Rectangular boxes in the top row show reference atlas position for images at the bottom. Scale bar, $500 \mu \mathrm{m}$. $\boldsymbol{D}$, Mean fluorescence density of the synaptophysin-tdTomato signals in brain regions targeted by AGRP neurons. $N=4$. AU, Arbitrary unit. Each black circle represents an animal. Data are presented as mean \pm SEM.

of 8 starved females displayed the behavior, compared with 8 of 8 under the fed condition (Table 1). By contrast, pup contact, locomotion, or the total duration that females crouch over pups did not change after starvation (Table 1). Together, these results show that FD hinders specific components of maternal care.

To see whether activation of AGRP neurons could similarly affect pup retrieval and maternal nest-building, we implanted optic fibers in the arcuate nucleus in AGRP ${ }^{\mathrm{ChR} 2}$ females to optogenetically stimulate AGRP neurons. Consistent with previous results (Aponte et al., 2011; Atasoy et al., 2012), light stimulation induced c-Fos expression in AGRP neurons (Fig. $3 A ; N=3$ ) and feeding $(N=27$, no light: $0.18 \pm 0.01 \mathrm{~g}$ vs light: $0.37 \pm 0.03 \mathrm{~g}$, paired two-tailed $t$ test, $t=13.51, \mathrm{df}=26, p<0.0001$; Fig. $3 B$ ). Subsequently, we analyzed maternal behaviors of AGRP ${ }^{\mathrm{ChR} 2}$ fe- 
A

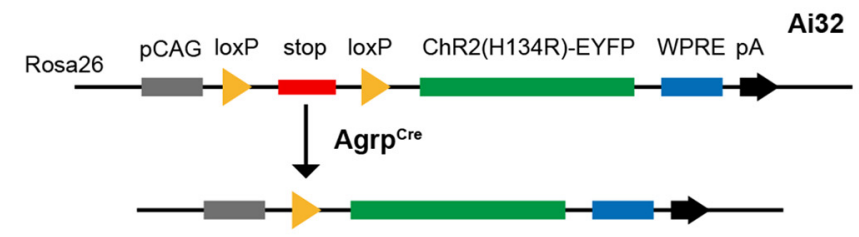

C

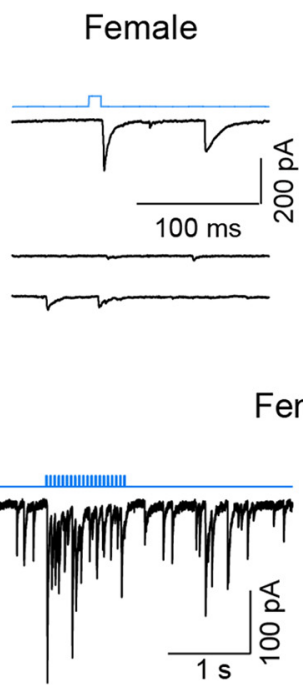

Male
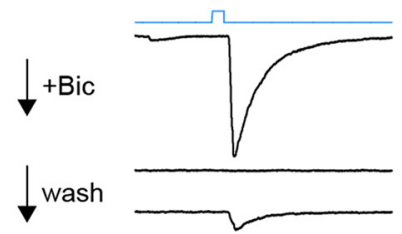

E

Female

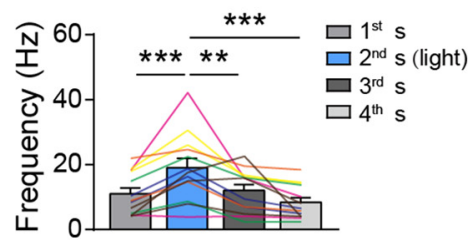

B
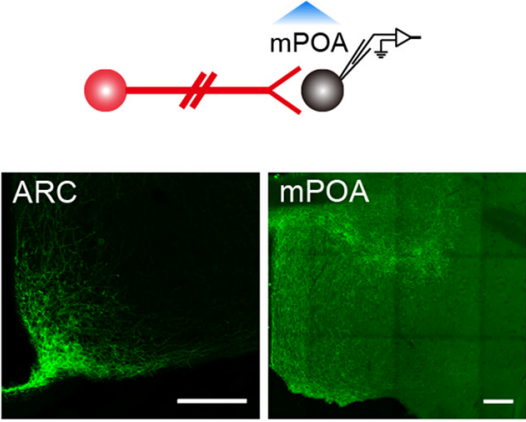

D

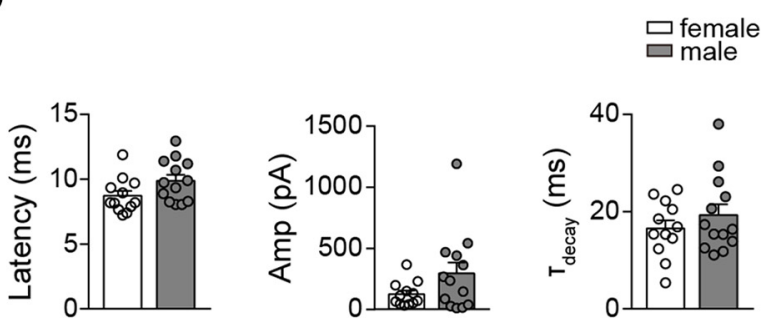

$\mathbf{F}$

Male

Figure 2. AGRP neurons form inhibitory synapses onto mPOA neurons. A, Illustration of the genetic strategy to optogenetically activate AGRP neurons and terminals. Cre induces excision of the stop codon to allow expression of ChR2 fused with EYFP in AGRP neurons and terminals. B, Schematics showing brain slice recording to identify mPOA neurons downstream of AGRP neurons. Representative images at the bottom show EYFP signal in the ARC and the mPOA. Scale bar, $200 \mu \mathrm{m}$. C, Representative traces of light-induced IPSCs in mPOA neurons in female (left) and male (right) by a single light pulse as indicated by the top blue line, which can be blocked by addition of Bicuculline (Bic) and recover after wash. $N=3$ cells from 1 female and 2 cells from 1 male. $D$, Quantification of the latency, amplitude (Amp), and decay time constant $(\tau)$ of IPSCs recorded in mPOA neurons in female and male AGRP ChR2 animals, respectively. $N=12$ cells from 6 AGRP ${ }^{\text {ChR2 }}$ females and 13 cells from 5 AGRP ${ }^{\text {ChR2 }}$ males as represented by open and filled circles respectively. $E, F$, Left, Representative trace of light-induced IPSCs in mPOA neurons by a train of light as indicated by the top blue line. Right, Quantification of IPSC frequency in 1 s segments before, during, and after light stimulation. $N=13$ cells from 6 AGRP ${ }^{\text {ChR2 }}$ females and 15 cells from 5 AGRP ${ }^{\text {ChR2 }}$ males. The same color lines denote cells recorded from the same animals. All bar values are presented as mean \pm SEM. ${ }^{* *} p<0.01 ;{ }^{* * *} p<0.001$.

Table 1. FD suppresses distinct components of maternal care

\begin{tabular}{|c|c|c|c|c|c|}
\hline \multirow[b]{2}{*}{ Behavior } & \multirow[b]{2}{*}{ Parameter } & \multicolumn{2}{|c|}{ Condition } & \multirow[b]{2}{*}{ Statistical test } & \multirow[b]{2}{*}{$p$} \\
\hline & & Ad libitum & Starvation & & \\
\hline \multirow[t]{3}{*}{ Pup contact } & Animals, $\%$ & $8 / 8$ & $8 / 8$ & Fisher's test & 1 \\
\hline & Count & $15.3 \pm 2.2$ & $14.6 \pm 3.6$ & Paired two-tailed $t$ test & $0.89(t=0.1433, \mathrm{df}=7)$ \\
\hline & Latency, s & $8.4 \pm 3.4$ & $5.5 \pm 2.4$ & Wilcoxon matched-pairs signed rank test & 0.74 (sum of signed rank $=-6$ ) \\
\hline \multirow[t]{3}{*}{ Pup retrieval } & Animals, $\%$ & $8 / 8$ & $6 / 8$ & Fisher's test & 0.47 \\
\hline & Count & $5.0 \pm 0.7$ & $4.8 \pm 1.4$ & Paired two-tailed $t$ test & $0.88(t=0.1510, d f=7)$ \\
\hline & Latency, s & $13.2 \pm 3.4$ & $65.8 \pm 16.7$ & Mann Whitney test & $0.0007(U=0)$ \\
\hline \multirow[t]{2}{*}{ Retrieval finish } & Animals, $\%$ & $8 / 8$ & $3 / 8$ & Fisher's test & 0.020 \\
\hline & Latency & $102.4 \pm 31.7$ & $561.3 \pm 157.8$ & Mann Whitney test & $0.0121(d f=0)$ \\
\hline \multirow[t]{2}{*}{ Maternal nest-building } & Animals, $\%$ & $8 / 8$ & $1 / 8$ & Fisher's test & 0.001 \\
\hline & Total duration, $\mathrm{s}$ & $81.4 \pm 21.0$ & $4.9 \pm 4.9$ & Wilcoxon matched-pairs signed rank test & 0.008 (sum of signed rank $=-36$ ) \\
\hline \multirow[t]{2}{*}{ Crouching } & Animals, $\%$ & $8 / 8$ & $8 / 8$ & Fisher's test & 1 \\
\hline & Total duration, $s$ & $357.8 \pm 35.8$ & $408.9 \pm 95.8$ & Paired two-tailed $t$ test & $0.59(t=0.5608, \mathrm{df}=7)$ \\
\hline Locomotion, $\mathrm{mm} / \mathrm{s}$ & & $34.5 \pm 2.8$ & $44.3 \pm 6.6$ & Paired two-tailed $t$ test & $0.23(t=1.316, \mathrm{df}=7)$ \\
\hline
\end{tabular}

males toward scattered pups with or without light stimulation (Fig. $3 C$ ). As a control, we implanted AGRP ${ }^{\text {Cre }}$ females with optic fibers and showed that photostimulation in these animals had no adverse effects on pup contact, pup retrieval or maternal nest-building $(N=$ 7, pup contact, latency, no light: $59.36 \pm 28.4$ s vs light: $34.04 \pm 20.06$ $\mathrm{s}$, Wilcoxon matched-pairs signed rank test, sum of signed ranks $=$ $-28, p=0.0156$, count, no light: $17.33 \pm 2.23$ vs light: $17.1 \pm 2.84$, paired two-tailed $t$ test, $p=0.857$; Fig. $3 D$; pup retrieval, \%trial, no light: $100 \%$ vs light: $100 \%$, score, no light: 3 vs light: $2.95 \pm 0.05$, Wilcoxon matched-pairs signed rank test, sum of signed ranks $=$ 
A
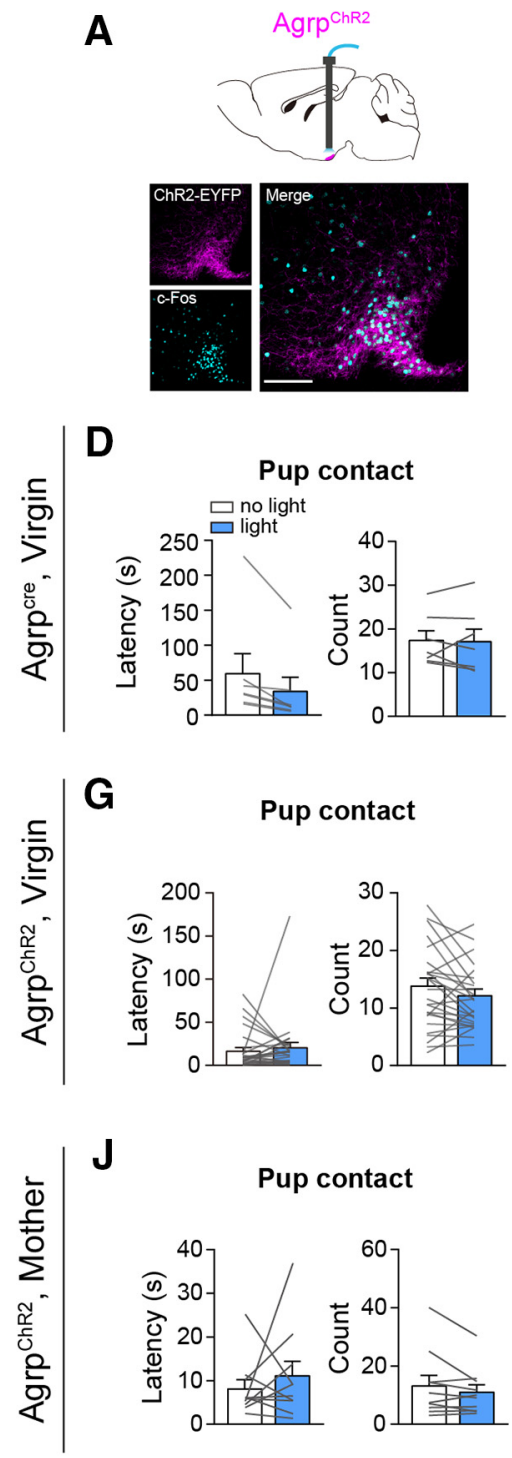

B

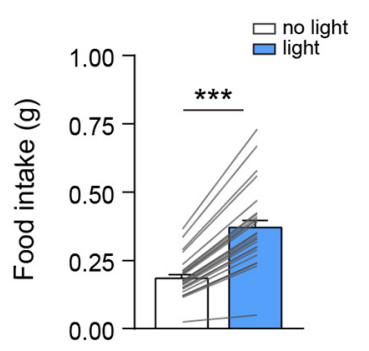

E

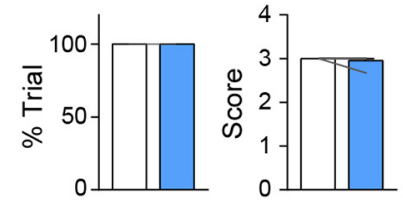

H

Pup retrieval
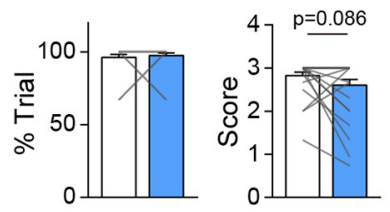

K

Pup retrieval
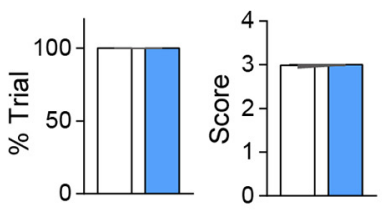

C

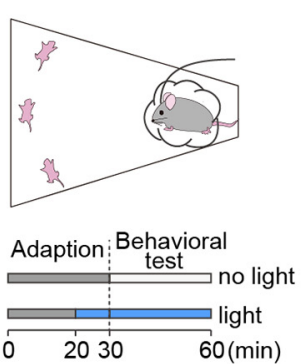

F

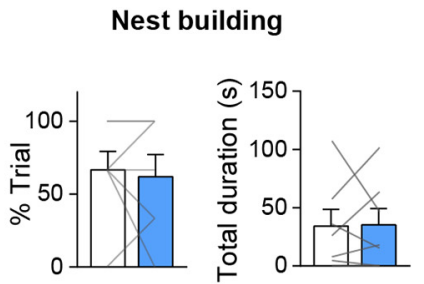

\section{I}

Nest building

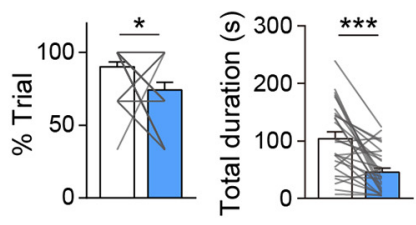

$\mathbf{L}$
Nest building

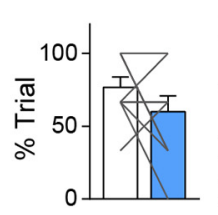

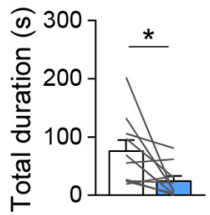

Figure 3. Optogenetic stimulation of AGRP neurons suppresses maternal nest-building. $A$, Schematics showing implantation of optic fibers in ARC in AGRP ChR2 females to test how activation of AGRP neurons affects maternal behaviors. Representative images at the bottom showing colocalization of ChR2 as analyzed by staining of EYFP and c-Fos after light stimulation. Scale bar, $100 \mu \mathrm{m}$. B, Food intake in $30 \mathrm{~min} . N=27$. C, Schematics of maternal behavioral test and the light stimulation pattern in "no light" and "light" trial. In either trial, external fiber was attached to the implanted fiber and animals were allowed to explore the cage for $\sim 30 \mathrm{~min}$ as the "adaptation period". In the last $10 \mathrm{~min}$ of this adaptation period, laser was turned on and stayed on continuously in "light" trial. Scattered pups were introduced into the cage at the end of the adaptation period to the edge furthest away from the nest. $\boldsymbol{D}-\boldsymbol{F}$, In virgin AGRP ${ }^{\text {Cre }}$ animals implanted with optic fibers, light stimulation did not adversely affect the latency or the count of pup contact behavior $(\boldsymbol{D})$, or the percentage of trials (\%trial) that animals displayed pup retrieval or the number of pups that were retrieved to the nest (score; see Materials and Methods; $\boldsymbol{E}$ ), or the percentage of trials that animals displayed maternal nest-building or the total duration devoted to this behavior in each trial $(\boldsymbol{F})$. $N=7 . \mathbf{G}-\mathbf{I}$, In virgin AGRP ChR2 animals, light stimulation did not affect the latency or count of pup contact behavior $(\boldsymbol{G})$, or the percentage of trials that animals displayed pup retrieval or the number of pups that were brought to the nest (score; $\boldsymbol{H}$ ), but significantly decreased the percentage of trials that animals displayed maternal nest-building and the total duration devoted to this behavior in each trial $(I) . N=27 . J-L$, In mother AGRP ChR2 animals, light stimulation did not affect the latency or count of pup contact behavior $(J)$, or the percentage of trials that animals displayed pup retrieval and the number of pups that were brought to the nest (score; $\boldsymbol{K}$ ), but significantly decreased the total duration devoted to maternal nest-building in each trial without affecting the percentage of trials that animals displayed the behavior $(\boldsymbol{L}) . N=10$. All values are presented as mean \pm SEM. Each gray line indicates paired values from an individual animal. ${ }^{*} p<0.05$; ${ }^{* * *} p<0.001$.

$-1, p>0.999$; Fig. $3 E$; nest-building, \%trial, no light: $66.67 \pm 12.6 \%$ vs light: $61.9 \pm 15.31 \%$, Wilcoxon matched-pairs signed rank test, sum of signed ranks $=-4, p>0.625$, total duration, no light: $34.2 \pm$ $14.41 \mathrm{~s}$ vs light: $35.18 \pm 14.19 \mathrm{~s}$, paired two-tailed $t$ test, $t=0.0727$, $\mathrm{df}=6, p=0.944$; Fig. $3 F$ ), indicating that light delivery alone does not impede maternal care.

In AGRP ${ }^{\mathrm{ChR} 2}$ females tested as virgins, optogenetic stimulation did not affect pup contact or pup retrieval (Wilcoxon matched-pairs signed rank test, $N=27$, pup contact, latency, no light: $16.62 \pm$ 4.23 s vs light: $20.48 \pm 6.24$ s, sum of signed ranks $=68, p=0.427$, count, no light: $13.79 \pm 1.43$ vs light: $12.12 \pm 1.15$, sum of signed ranks $=-126, p=0.112$; Fig. $3 G$; pup retrieval, \%trial, no light: $96.3 \pm 2.05 \%$ vs light: $97.53 \pm 1.71 \%$, sum of signed ranks $=3, p>$ 0.999 , score, no light: $2.83 \pm 0.08$ vs light: $2.60 \pm 0.13$, sum of signed ranks $=-39, p=0.0859$; Fig. $3 H)$, but strongly suppressed maternal nest-building resulting in a drop in the occurrence of the behavior and at the same time a $\sim 60 \%$ decrease in the total duration of nest-building (Wilcoxon matched-pairs signed rank test, $N=27$, \%trial, no light: $90.12 \pm 3.48 \%$ vs light: $74.07 \pm 5.44 \%$, sum of signed ranks $=-79, p=0.0258$, total duration, no light: $103.9 \pm$ 11.77 s vs light: $45.43 \pm 7.41 \mathrm{~s}$, sum of signed ranks $=-318, p<$ 0.0001; Fig. $3 I)$. Correspondingly, nest quality score was also signif- 
Table 2. Optogenetic stimulation of AGRP neurons does not affect general behaviors or body temperature in AGRP ${ }^{\text {ChR2 }}$ females

\begin{tabular}{|c|c|c|c|c|c|c|c|}
\hline & Unit & No light & Light & Statistical test & & $p$ & $N$ \\
\hline Locomotion speed & $\mathrm{mm} / \mathrm{s}$ & $92.9 \pm 13.9$ & $92.5 \pm 13.6$ & Mann Whitney test & U: 332 & 0.98 & 19 \\
\hline Core body temperature & ${ }^{\circ} \mathrm{C}$ & $37.5 \pm 0.3$ & $37.6 \pm 0.3$ & Wilcoxon matched-pairs signed rank test & W: 1 & 0.5 & 3 \\
\hline Rearing & $s$ & $25.5 \pm 6.7$ & $25.7 \pm 9.5$ & Wilcoxon matched-pairs signed rank test & W: 54 & 0.1 & 19 \\
\hline Digging & $s$ & $70.2 \pm 16.0$ & $46.2 \pm 13.3$ & Wilcoxon matched-pairs signed rank test & W: 61 & 0.3 & 19 \\
\hline Grooming & $S$ & $6.8 \pm 2.8$ & $5.5 \pm 2.7$ & Wilcoxon matched-pairs signed rank test & W: 19 & 0.73 & 19 \\
\hline
\end{tabular}

W, Sum of signed rank.

icantly decreased when scattered nest materials were provided at the beginning of the behavioral test $(N=8$, no light: $3.85 \pm 0.53$ vs light: $2.69 \pm 0.45$, Wilcoxon matched-pairs signed rank test, sum of signed ranks $=24, p=0.0469$ ).

Because parturition is known to improve maternal behaviors in rodents (Bridges, 1975; Dulac et al., 2014; Wu et al., 2014), we therefore also tested the effects of activating AGRP neurons on maternal behaviors in mothers. To do so, we mated AGRP ChR2 females to deliver pups and tested their behaviors toward their own pups during lactation. In mother AGRP ${ }^{\mathrm{ChR} 2}$ females, light stimulation similarly reduced the total duration of maternal nestbuilding without affecting the occurrence of the behavior or impairing pup contact or pup retrieval (Wilcoxon matched-pairs signed rank test, $N=10$, pup contact, latency, no light: $8.09 \pm$ $2.08 \mathrm{~s}$ vs light: $11.07 \pm 3.38 \mathrm{~s}$, sum of signed ranks $=7, p=0.770$, count, no light: $13.17 \pm 3.62$ vs light: $11 \pm 2.53, p=0.336$; Fig. $3 J$; pup retrieval, \%trial, no light: $100 \%$ vs light: $100 \%$, score, no light: $2.99 \pm 0.007$ vs light: 3 , sum of signed ranks $=3, p=0.5$; Fig. $3 K$; nest-building, \%trial, no light: $76.67 \pm 7.12 \%$ vs light: $60 \pm 10.89 \%$, sum of signed ranks $=-14, p=0.188$, total duration, light: $75.81 \pm 18.83$ s vs light: $24.5 \pm 8.78 \mathrm{~s}, p=0.0195$; Fig. $3 L$ ). Crucially, locomotion speed, core body temperature and other home cage activities were not changed under light stimulation in either virgin or mother AGRP ${ }^{\mathrm{ChR} 2}$ females (Table 2). Together, these results show that optogenetic activation of AGRP neurons strongly suppress maternal nest-building.

\section{Activation of $A G R P \rightarrow$ mPOA projections suppresses maternal nest-building}

To test whether activating AGRP projections to the mPOA or other brain areas alone can affect maternal care, we implanted optic fibers into the mPOA, PVH or LHA in virgin AGRP ${ }^{\text {ChR2 }}$ females and tested their behaviors toward scattered pups with or without light stimulation (Fig. 4A,E,I). As expected, activation of $\mathrm{AGRP} \rightarrow \mathrm{PVH}$ or AGRP $\rightarrow$ LHA projections elicited robust food intake (paired two-tailed $t$ test, $\mathrm{PVH}, N=8$, no light: $0.04 \pm$ 0.01 g vs light: $0.22 \pm 0.02 \mathrm{~g}, t=10.09, \mathrm{df}=7, p<0.0001$; Fig. $4 F$; LHA, $\mathrm{N}=8$, no light: $0.05 \pm 0.01 \mathrm{~g}$ vs light: $0.24 \pm 0.04 \mathrm{~g}$, paired two-tailed $t$ test, $t=4.593, \mathrm{df}=6, p=0.0037$; Fig. $4 J)$. In comparison, activation of $\mathrm{AGRP} \rightarrow \mathrm{mPOA}$ projections elicited feeding in a subset of tested animals ( 4 of $8 ; N=8$, no light: $0.03 \pm 0.01 \mathrm{~g}$ vs light: $0.15 \pm 0.05 \mathrm{~g}$, paired two-tailed $t$ test, $t=$ 2.247, df $=7, p=0.0594$; Fig. $4 B$ ). Furthermore, stimulation of $\mathrm{AGRP} \rightarrow \mathrm{mPOA}$ or $\mathrm{AGRP} \rightarrow \mathrm{PVH}$ projections but not $\mathrm{AGRP} \rightarrow \mathrm{LHA}$ projections suppressed total duration of maternal nest-building (mPOA, $N=18$, Wilcoxon matched-pairs signed rank test, \%trial, no light: $87.04 \pm 3.94 \%$ vs light: $77.78 \pm 7.13 \%$, sum of signed ranks $=-24, p=0.125$, total duration, no light: $85.32 \pm$ 13.49 s v light: $46.49 \pm 13.21 \mathrm{~s}$, sum of signed ranks $=-131, p=$ 0.0028; Fig. $4 D$; PVH, $N=8$, \%trial, no light: $95.83 \pm 4.17 \%$ vs light: $75 \pm 8.33 \%$, Wilcoxon matched-pairs signed rank test, sum of signed ranks $=-15, p=0.188$, total duration, no light: $77.04 \pm 13.76 \mathrm{~s}$ vs light: $28.64 \pm 6.02 \mathrm{~s}$, paired two-tailed $t$ test, $t=3.132, \mathrm{df}=7, p=0.0166$; Fig. $4 H$; LHA, $N=7$, Wilcoxon matched-pairs signed rank test, \%trial, no light: $61.9 \pm 1.84 \%$ vs light: $66.67 \pm 7.27 \%$, sum of signed ranks $=7, p=0.594$, total duration, no light: $25.7 \pm 12.7$ s vs light: $26.85 \pm 7.89$ s, sum of signed rank $=28, p=0.9375$; Fig. $4 L$ ). In addition, stimulating AGRP $\rightarrow$ mPOA but not the other two pathways also led to a slight decrease in pup retrieval score (mPOA, $N=18$, Wilcoxon matched-pairs signed rank test, \%trial, no light: $94.44 \pm 4.04 \%$ vs light: $92.59 \pm 4.31 \%$, sum of signed ranks $=-1, p>0.999$, score, no light: $2.74 \pm 0.13$ vs light: $2.46 \pm 0.16$, sum of signed ranks $=$ $-45, p=0.0195$; Fig. 4C; PVH, $N=8$, Wilcoxon matched-pairs signed rank test, \%trial, no light: $95.83 \pm 4.17 \%$ vs light: $75 \pm$ $8.33 \%$, sum of signed ranks $=-15, p=0.188$, score, no light: $2.92 \pm 0.08$ vs light: $2.65 \pm 0.17$, sum of signed ranks $=-9, p=$ 0.312; Fig. $4 G$; LHA, $N=7$, paired two-tailed $t$ test, \%trial, no light: $71.43 \pm 11.34 \%$ vs light: $71.43 \pm 11.34 \%, t=0, \mathrm{df}=6, p=$ 1 , score, no light: $2.23 \pm 0.26$ vs light: $2.43 \pm 0.21, t=0.8572$, $\mathrm{df}=6, p=0.4242$; Fig. $4 K$ ), which is reminiscent of pup retrieval deficits observed with acute FD (Table 1). Thus, activation of $\mathrm{AGRP} \rightarrow \mathrm{mPOA}$ or $\mathrm{AGRP} \rightarrow \mathrm{PVH}$ projections but not AGRP $\rightarrow$ LHA projections suppresses maternal nest-building.

\section{Chemogenetic inhibition of mPOA Vgat + neurons reduces maternal nest-building}

One potential confounding factor with the above terminal stimulation experiments is that it is difficult to discern whether the observed behavioral effects could be because of unintended stimulation of AGRP fibers of passage to other brain areas, especially considering the proximity of $\mathrm{mPOA}$ and PVH and with other targets of AGRP neurons (Betley et al., 2013). As such, we sought to directly target $\mathrm{mPOA}$ neurons to see whether the observed suppression on maternal nest-building by stimulation of $\mathrm{AGRP} \rightarrow \mathrm{mPOA}$ projections can be reproduced by inhibition of mPOA neurons. To do this, we first performed single-cell RTPCR after whole-cell recordings (Fig. $5 A$ ) and found that all lightresponsive $\mathrm{mPOA}$ neurons expressed Vgat (9 of 9; Fig. 5B), even though the mPOA contains both Vgat + and Vglut2+ neurons (Wei et al., 2018). Next, we locally injected adeno-associated viruses (AAVs) encoding Cre-inducible HM4D, or mCherry as the control, into the mPOA of Vgat-Ires-Cre females (Fig. 5C,D). Post hoc histological analysis revealed that viral expression was mostly restricted to the $\mathrm{mPOA}$ with an estimated spread of $\sim 960 \pm 54 \mu \mathrm{m}$ along the anterior-posterior axis and an infection rate of $\sim 20 \pm 2 \%$ of Nissl + cells in the targeted region $(N=3)$. As expected, CNO perfusion in brain slices lowered the membrane potential of HM4D infected neurons and reduced the firing rates of these neurons (5/5; Fig. 5E; Krashes et al., 2013). Behaviorally, we found that $\mathrm{CNO}$ administration compared with saline significantly reduced the total duration of maternal nestbuilding but not the occurrence of the behavior in HM4D transduced animals but not the controls (control, $N=14$, Wilcoxon matched-pairs signed rank test, \%trial, saline $75 \pm 8.69 \%$ vs CNO $75 \pm 8.69 \%$, sum of signed rank $=0, p=1$, total duration, 
A

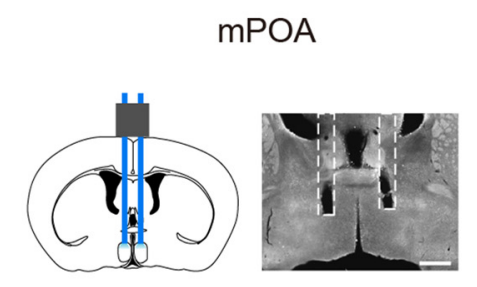

E

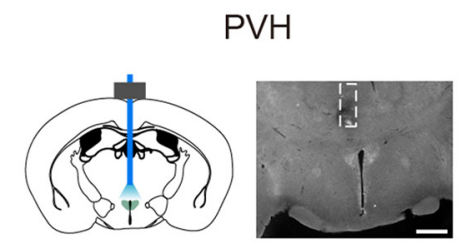

I

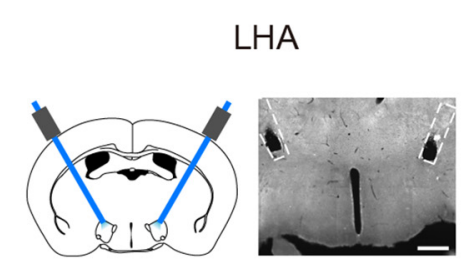

B

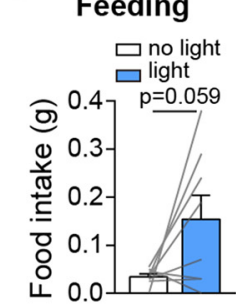

F

Feeding

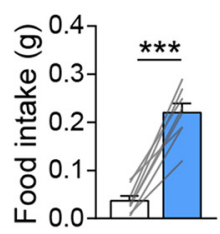

J
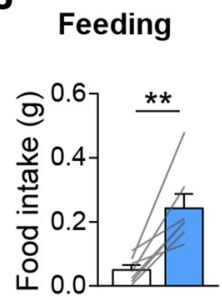

C
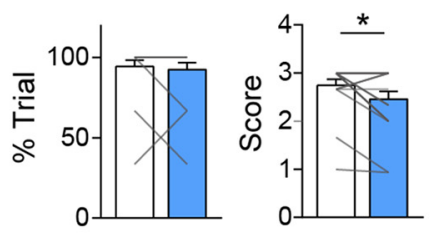

G
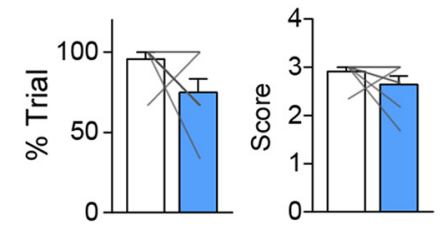

K

Pup retrieval

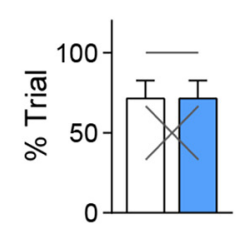

Pup retrieval

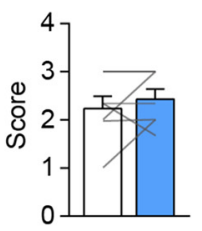

L

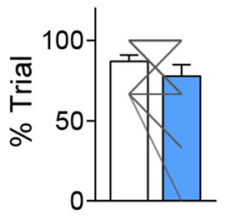

H

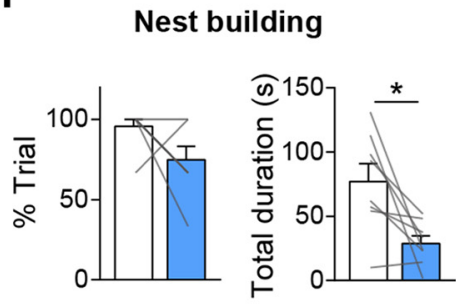

D

Nest building

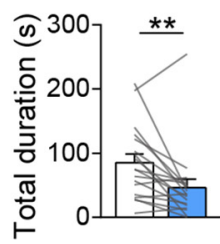

Nest building

\section{Nest building}

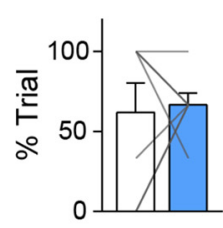

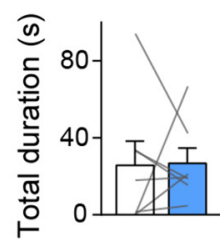

Figure 4. Optogenetic stimulation of AGRP projections to MPOA, PVH or LHA differentially affect maternal care. $A$, Schematics on the left and a presentative image on the right showing implantation of bilateral fibers into the mPOA. $N=18$. $\boldsymbol{B}$, Light stimulation of AGRP $\rightarrow \mathrm{mPOA}$ projections in virgin AGRP ${ }^{\text {ChR2 }}$ females promote food intake over 30 min. $\boldsymbol{C}, \boldsymbol{D}$, Light stimulation of $\mathrm{AGRP} \rightarrow \mathrm{MPOA}$ projections did not affect the percentage of trials (\%trial) that animals displayed pup retrieval but slightly decreased the pup retrieval score $(\boldsymbol{C})$ and significantly reduced the total duration devoted to maternal nest-building in each trial without affecting the percentage of trials that animals displayed the behavior $(\boldsymbol{D})$. $\boldsymbol{E}$, Schematics on the left and a presentative image on the right showing unilateral implantation of fibers into the PVH. $N=8$. $\boldsymbol{F}-\boldsymbol{H}$, Light stimulation of AGRP $\rightarrow$ PVH projections in virgin AGRP ${ }^{\mathrm{ChR} 2}$ female animals promoted feeding $(\boldsymbol{F})$, did not affect the percentage of trials that animals displayed pup retrieval or the number of pups that were brought to the nest (score; $\boldsymbol{G}$ ), or the percentage of trials that animals displayed maternal nest-building but decreased the total duration devoted to nest-building in each trial $(\boldsymbol{H}) . \boldsymbol{I}$, Schematics on the left and a presentative image on the right showing bilateral implantation of fibers into the $L H A . N=7$. $J-L$, Light stimulation of AGRP $\rightarrow$ LH projections in virgin AGRP ChR2 female animals promoted feeding $(J)$, did not affect the percentage of trials that animals displayed pup retrieval or the number of pups that were brought to the nest (score; $\boldsymbol{K}$ ), or the percentage of trials that animals displayed maternal nest-building or the total duration devoted to it in each trial ( $\boldsymbol{L}$ ). Scale bar, $500 \mu \mathrm{m}$. All values are presented as mean \pm SEM. Each gray line indicates values from an individual animal. ${ }^{*} p<0.05 ;{ }^{* *} p<0.01 ;{ }^{* * *} p<0.001$.

saline $47.43 \pm 10.12 \mathrm{~s}$ vs CNO $52.44 \pm 13.39 \mathrm{~s}$, sum of signed rank $=9, p=0.7869 ; \mathrm{HM} 4 \mathrm{D}, N=12$ \%trial, saline $87.5 \pm$ $6.53 \%$ vs $\mathrm{CNO} 75 \pm 7.54 \%$, Wilcoxon matched-pairs signed rank test, sum of signed rank $=-9, p=0.375$, total duration, saline $53.71 \pm 9.09 \mathrm{~s}$ vs CNO $29.58 \pm 5.54 \mathrm{~s}$, paired two-tailed test, $t=$ 2.832, $\mathrm{df}=11, p=0.0163$; Fig. $5 G$ ). By comparison, $\mathrm{CNO}$ administration did not affect pup retrieval in either group (Wilcoxon matched-pairs signed rank test, control, $N=14$, \%trial, saline $96.43 \pm 3.57 \%$ vs CNO $96.43 \pm 3.57 \%$, sum of signed rank $=0, p=1$, score, saline $2.79 \pm 0.12$ vs CNO $2.78 \pm 0.11$, sum of signed rank $=2, p=0.875 ; \mathrm{HM} 4 \mathrm{D}, N=12$, \%trial, saline $100 \%$ vs CNO $87.5 \pm 6.53 \%$, sum of signed rank $=-6, p=0.25$, score, saline $2.99 \pm 0.01$ vs CNO $2.63 \pm 0.17$, sum of signed rank $=-13, p=0.125$; Fig. $5 F)$. These results mirror behavioral deficits observed when we optogenetically stimulating AGRP $\rightarrow$ mPOA projections. On the other hand, food intake was not affected by $\mathrm{CNO}$ in either HM4D or control group $(>2 \mathrm{~h}$, mCherry, $N=4$, saline $0.22 \pm 0.07 \mathrm{~g}$ vs $\mathrm{CNO}, 0.19 \pm 0.03 \mathrm{~g}$, Wilcoxon matched-pairs signed rank test, sum of signed ranks = $0, p>0.9999$; HM4D, $N=12$, saline $0.24 \pm 0.03 \mathrm{~g}$ vs $\mathrm{CNO}$ $0.24 \pm 0.04 \mathrm{~g}$, paired two-tailed $t$ test, $t=0.02054, \mathrm{df}=11, p=$ 0.984 ), which raises the possibility that increased food intake observed in a subset of animals when stimulating AGRP $\rightarrow \mathrm{mPOA}$ projections (Fig. $4 B$ ) may be because of additional activation of AGRP projections to other brain areas.

Along this line, we also chemogenetically inhibited LHA Vglut2 + neurons, another population of hypothalamic neurons critical for feeding and innate drives (Jennings et al., 2013; Y. Li et al., 2018). To this end, we bilaterally injected AAVs encoding Cre-inducible HM4D, or mCherry as the control, into the LHA of Vglut2-Ires-Cre females (Fig. 6A-C). Post hoc histological analysis revealed that HM4D expression was mostly restricted to the LHA with an estimated spread of $\sim 918 \pm 28 \mu \mathrm{m}$ along the anterior-posterior axis $(N=11)$ and an estimated infection rate of $\sim 25 \pm 2 \%$ of Nissl+ cells in the region $(N=3)$. Behaviorally, we found that $\mathrm{CNO}$ administration compared with saline significantly increased food intake in HM4D transduced animals but not the controls (paired two-tailed $t$ test, control, $N=8,1 \mathrm{~h}$, saline $0.15 \pm 0.05 \mathrm{~g}$ vs CNO $0.18 \pm 0.05 \mathrm{~g}, t=0.6759, \mathrm{df}=7, p=0.521,2 \mathrm{~h}$, saline $0.20 \pm 0.06 \mathrm{~g}$ vs CNO $0.29 \pm 0.08 \mathrm{~g}, t=1.138 \mathrm{df}=7, p=$ $0.293,3 \mathrm{~h}$, saline $0.37 \pm 0.09 \mathrm{~g}$ vs CNO $0.37 \pm 0.09 \mathrm{~g}, t=$ $0.02530, \mathrm{df}=7, p=0.981,6 \mathrm{~h}$, saline $0.64 \pm 0.11 \mathrm{~g}$ vs $\mathrm{CNO}$ $0.68 \pm 0.11 \mathrm{~g}, t=0.3572, \mathrm{df}=7, p=0.732$; HM4D, $N=11$, $1 \mathrm{~h}$, saline $0.17 \pm 0.04 \mathrm{~g}$ vs CNO $0.28 \pm 0.05 \mathrm{~g}, t=1.638, \mathrm{df}=$ $10, p=0.132,2 \mathrm{~h}$, saline $0.22 \pm 0.04 \mathrm{~g}$ vs CNO $0.40 \pm 0.07 \mathrm{~g}$, 
A
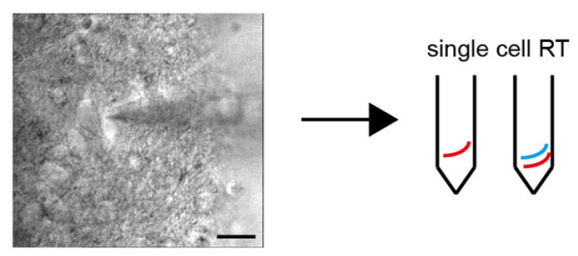

C

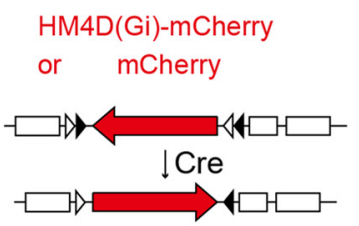

D

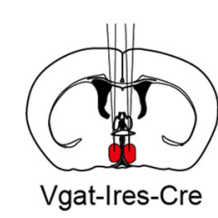

F

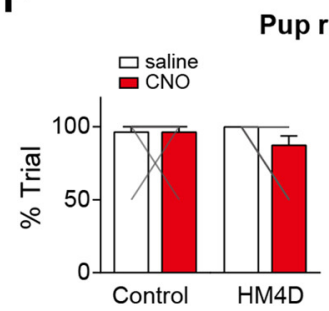

Pup retrieval

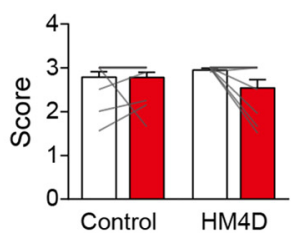

B

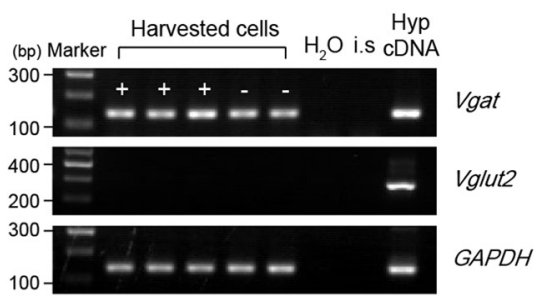

E

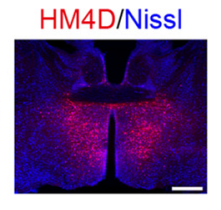

G

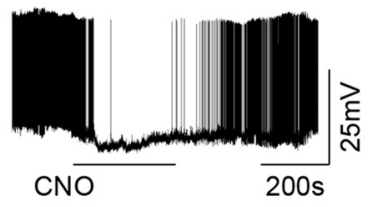

Nest building

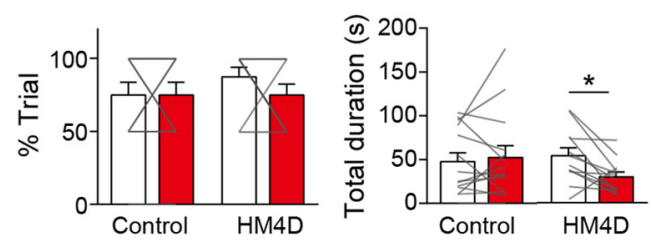

Figure 5. Chemogenetic inhibition of mPOA Vgat + neurons suppresses maternal nest-building. A, Schematic illustration of single-cell RT-PCR procedure. After brain slice recording of mPOA neurons in females, contents in the recording pipette were released into tubes and proceeded for RT reaction followed by PCR amplification. Scale bar, $20 \mu \mathrm{m}$. $\boldsymbol{B}$, A representative agarose gel image showing single-cell RT-PCR analysis of recorded mPOA neurons with primers against genes indicated on the right. " +" indicating light responsive cells; " - "indicating nonresponsive cells. $\mathrm{H}_{2} \mathrm{O}$ and internal solution (i.s.) served as negative controls and diluted hypothalamus (DNA (Hyp (DNA) was used as the positive control. Maker size indicated on the left. All light responsive mPOA neurons express Vgat. C, Depicting molecular constructs of AAVs encoding Cre-inducible HM4D fused with mCherry driven by human synapsin promoter or mCherry driven by EF1a promoter as the control. $D$, Schematics on the left and a representative image on the right showing bilateral injection of AAVs encoding Cre-inducible HM4D into the mPOA of virgin Vgat-Ires-Cre animals. Scale bar, $500 \mu \mathrm{m}$. $\boldsymbol{E}$, Perfusion of CNO lowered the membrane potential and inhibited firing of HM4D-expressing neurons. $N=5$ cells. $\boldsymbol{F}, \boldsymbol{G}$, Intraperitoneal injection of CNO compared with saline did not affect the percentage of trials (\%trial) that animals displayed pup retrieval and the number of pups that were brought to the nest (score; $\boldsymbol{F})$, but significantly decreased the total duration devoted to maternal nest-building in each trial without affecting the percentage of trials that animals displayed the behavior $(G) . N=12$ for HM4D group and 14 for mCherry group. All values are presented as mean \pm SEM. Each gray line indicates values from an individual animal. ${ }^{*} p<0.05$.

$t=2.223 \mathrm{df}=10, p=0.0504,3 \mathrm{~h}$, saline $0.31 \pm 0.05 \mathrm{~g}$ vs CNO $0.51 \pm 0.07 \mathrm{~g}, t=2.307, \mathrm{df}=10, p=0.0437,6 \mathrm{~h}$, saline $0.59 \pm$ $0.07 \mathrm{~g}$ vs CNO $0.78 \pm 0.10 \mathrm{~g}, t=1.608, \mathrm{df}=10, p=0.139$; Fig. $6 D)$. By contrast, $\mathrm{CNO}$ administration had little effects on pup contact, pup retrieval or maternal nest-building (pup contact: latency, mCherry, $N=8$, saline $3.93 \pm 1.39$ s vs CNO $4.55 \pm$ $1.27 \mathrm{~s}$, Wilcoxon matched-pairs signed rank test, sum of signed ranks $=10, p=0.547, \mathrm{HM} 4 \mathrm{D}, N=11$, saline $5.09 \pm$ $0.81 \mathrm{~s}$ vs CNO $7.27 \pm 1.62 \mathrm{~s}$, paired two-tailed $t$ test, $t=1.216$, $\mathrm{df}=10, p=0.253$; count, paired two-tailed $t$ test, mCherry, $N=8$, saline $38.06 \pm 5.63$ vs CNO $39.63 \pm 6.60, t=0.374$, $\mathrm{df}=7, p=0.720, \mathrm{HM} 4 \mathrm{D}, \mathrm{N}=11$, saline $39.55 \pm 4.82$ vs $\mathrm{CNO}$ $34.73 \pm 3.74, t=0.796, \mathrm{df}=10, p=0.445$; Fig. $6 E$; pup retrieval: \%trial, mCherry, $N=8$, saline $100 \%$ vs CNO $100 \%$, $p=1$, HM4D, $N=11$, saline $100 \%$ vs CNO $95.45 \pm 4.55 \%$, Wilcoxon matched-pairs signed rank test, sum of signed rank $=-1, p>0.999$; score, Wilcoxon matched-pairs signed rank test, mCherry, $N=8$, saline $2.88 \pm 0.13$ vs $\mathrm{CNO} 3$, sum of signed ranks $=1, p>0.999, \mathrm{HM} 4 \mathrm{D}, N=11$, saline $2.77 \pm$ 0.12 vs CNO $2.77 \pm 0.12$, sum of signed ranks $=1, p>0.999$; Fig. $6 F$; nest-building: \%trial, Wilcoxon matched-pairs signed rank test, mCherry, $N=8$, saline $93.75 \pm 6.25 \%$ vs $\mathrm{CNO}$ $100 \%$, sum of signed ranks $=1, p>0.999, \mathrm{HM} 4 \mathrm{D}, N=11$, saline $90.91 \pm 6.10 \%$ vs CNO $90.91 \pm 6.10 \%$, sum of signed ranks $=0, p>0.999$, total duration, paired two-tailed $t$ test,
mCherry, $N=8$, saline $63.91 \pm 15.16$ vs CNO $71.94 \pm 16.9$, $t=0.576, \mathrm{df}=7, p=0.582, \mathrm{HM} 4 \mathrm{D}, N=11$, saline $70.46 \pm$ 14.86 vs CNO 66.2 $\pm 11.12, t=0.313, \mathrm{df}=10, p=0.761$; Fig. $6 G)$. These results suggest that LHA Vglut $2+$ neurons unlikely regulate maternal care. Thus, although AGRP projections to other brain regions such as PVN may also play a role in modulating maternal care, these results nevertheless suggest at some levels the functional selectivity of $A G R P \rightarrow m P O A$ projections.

\section{Thermal challenge induced nest-building is not inhibited by AGRP $\rightarrow$ mPOA projections.}

Furthermore, as nest-building occurs not only as a component of maternal care but also as a thermal regulatory behavior (Bult and Lynch, 1997; Tan et al., 2016), we want to know whether suppression of nest-building by AGRP $\rightarrow$ mPOA projections is restricted to the context of maternal care. To answer this question, we exposed virgin AGRP ${ }^{\mathrm{ChR} 2}$ females implanted with bilateral optic fibers in the mPOA to $16^{\circ} \mathrm{C}$ air temperature for $4.5 \mathrm{~h}$ in a cage with scattered nest materials (Fig. 7A) while optogenetically stimulating AGRP $\rightarrow$ mPOA projections during alternating $1.5 \mathrm{~h}$ segments (Fig. $7 B$ ). Compared with the control condition, the percentage of trial that nest-building occurred and the total duration that an animal spent on nest-building was not reliably affected by optogenetic stimulation of AGRP terminals in the 
A

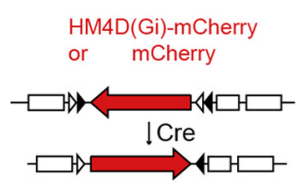

D

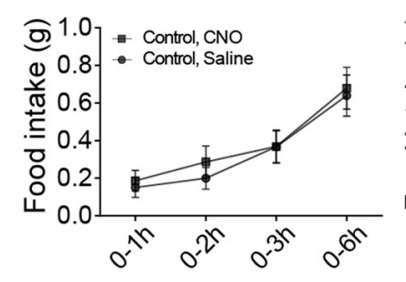

Feeding

F

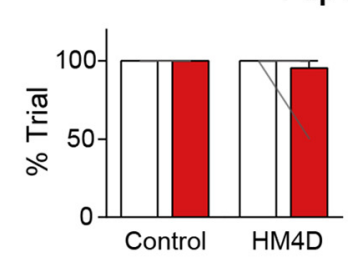

B

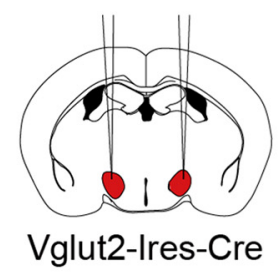

C

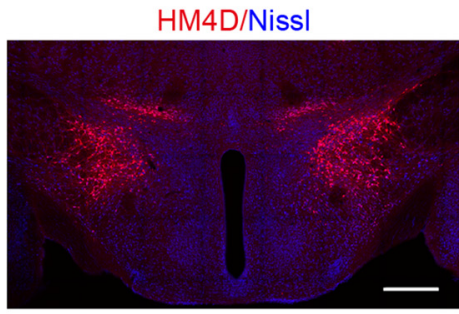

E

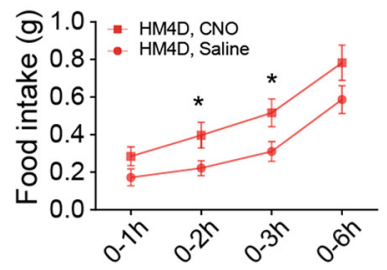

Pup contact
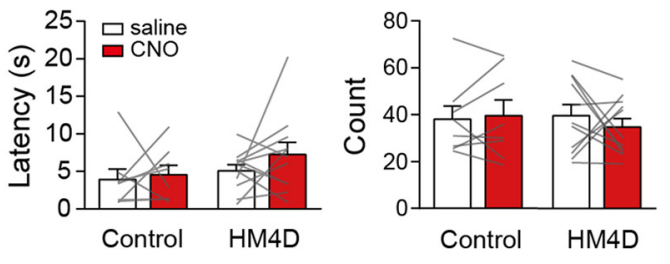

G

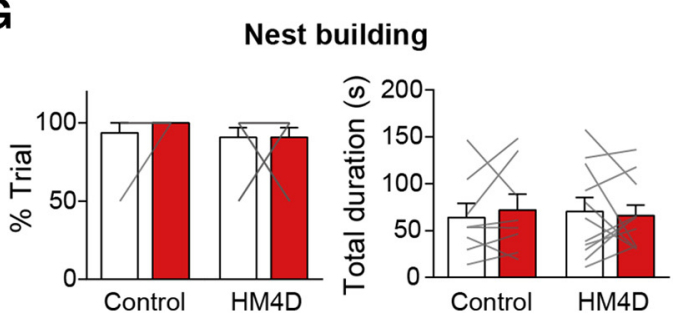

Figure 6. Chemogenetic inhibition of LHA Vglut2 + neurons increases feeding but has little effects on maternal care. $A$, Depicting molecular constructs of AAVs encoding Cre-inducible HM4D fused with mCherry driven by human synapsin promoter or mCherry driven by EF1a promoter as the control. $\boldsymbol{B}, \boldsymbol{C}, S$ chematics in $\boldsymbol{B}$ and a representative image in $\boldsymbol{C}$ showing bilateral injection of AAVs into the LHA of Vglut2-Ires-Cre females. Scale bar, $500 \mu \mathrm{m}$. D. Amount of food intake at different time point after intraperitoneal injection of saline or CN0 in control or HM4D group. $\boldsymbol{E}$, $\mathbf{G}$, Intraperitoneal injection of CNO compared with saline did not affect the latency or count of pup contact (E), or the percentage of trials (\%trial) that animals displayed pup retrieval and the number of pups that were brought to the nest (score; $\boldsymbol{F}$ ), or the percentage of trials that animals displayed maternal nest-building or the total duration of maternal nest-building $(\boldsymbol{G})$ in either HM4D or control group. $N=11$ for HM4D group and 8 for mCherry group. All values are presented as mean \pm SEM. Each gray line indicates values from an individual animal. ${ }^{*} p<0.05$.

mPOA (\%animal, Fisher's test, first, no light: $7 / 8$ vs light: $4 / 8, p=$ 0.282 , second, no light: $6 / 8$ vs light: $6 / 8, p=1$, third, no light: $5 / 8$ vs light: $5 / 8, p=1$; Fig. $7 C$; total duration, $N=8$, first, no light: $30.91 \pm 18.02 \mathrm{~s}$ vs light: $27.91 \pm 14.13 \mathrm{~s}$, Wilcoxon matched-pairs signed rank test, sum of signed ranks $=-2, p=0.945$, second, no light: $43.28 \pm 17.33 \mathrm{~s}$ vs light: $41.3 \pm 13.99 \mathrm{~s}$, paired two-tailed $t$ test, $t=0.086, \mathrm{df}=7, p=0.934$, third, no light: $20.98 \pm 7.52 \mathrm{~s}$ vs light: $9.98 \pm 4.55 \mathrm{~s}$, Wilcoxon matched-pairs signed rank test, sum of signed ranks $=14, p=0.297$; Fig. $7 D)$. Together, these results support the notion that $\mathrm{AGRP} \rightarrow \mathrm{mPOA}$ projections modulate nest-building particularly in the context of maternal care.

\section{Distinctive subsets of mPOA Vgat + neurons underlie pup retrieval and maternal nest-building}

In experiments described above, we show that optogenetic stimulation of AGRP $\rightarrow$ mPOA projections has minimum effects on pup retrieval but strongly inhibits maternal nest-building. Yet, we and others have shown previously that destruction of the mPOA or ablation of $\sim 80 \%$ of mPOA Vgat + neurons impairs both pup retrieval and maternal nest-building (Tsuneoka et al., 2013; Wei et al., 2018). To integrate these seemingly inconsistent results, we optogenetically activated and inhibited mPOA Vgat+ neurons (Fig. 8) and compared the behavioral outcome with optogenetic manipulation of mPOA Esr1+ neurons, which make up $\sim 50 \%$ of the mPOA Vgat + neurons and are known to promote pup-retrieval (Fang et al., 2018; Wei et al., 2018).

To this end, we first injected AAVs encoding Cre-dependent
ChR2 unilaterally into the mPOA of Vgat-Cre females and implanted optic fibers (Fig. 8A). Phasic activation of mPOA Vgat+ neurons $(12 \mathrm{~mW}, 10 \mathrm{~ms}, 40 \mathrm{~Hz}, 15 \mathrm{~s})$ in the presence of pups elicited light-locked display of pup retrieval behavior (mCherry, $N=5,0$, ChR2, $N=8,58.11 \pm 12.7 \%$, unpaired two-tailed $t$ test, $t=3.558, \mathrm{df}=11, p=0.0045$; Fig. $8 B$ ), which is similar to activation of mPOA Esr $1+$ neurons. Interestingly, the efficacy for light to induce pup retrieval was greater in Vgat-Cre females (Vgat-Cre, 8/8 vs Esr1-Cre, 5/10, $p=0.0359$, Fisher's test; Wei et al., 2018). Surprisingly, when animals were tested in the presence of nest materials, optogenetic stimulation of mPOA Vgat+ neurons but not Esr1 + neurons also promoted nest-building behavior (Vgat-Cre, 8/9 vs Esr1-Cre, 1/7, Fisher's exact test, $p=$ 0.0034 ) with a behavioral onset latency of $5.92 \pm 0.63 \mathrm{~s}$ after light delivery (Vgat, mCherry, $N=5,2.5 \pm 2.5 \%$, ChR2, $N=9$, $43.23 \pm 9.74 \%$, unpaired two-tailed $t$ test, $t=3.034, \mathrm{df}=12, p=$ 0.0104; Esr1, mCherry, $N=4,0 \%$, ChR2, $N=7,5.36 \pm 5.36 \%$, Mann-Whitney test, $U=12, p>0.999$, Vgat ChR2 vs Esr 1 ChR2, Mann-Whitney test, $U=7, p=0.0067$; Fig. $8 C$ ). These results indicate that the non-Esr1+ subset of mPOA Vgat+ neurons may play a more prominent role in driving maternal nestbuilding. Indeed, a recent study (Fang et al., 2018) using singleunit recordings in the $\mathrm{MPOA}$ has identified distinctive neuronal activation patterns in the mPOA associated with pup retrieval and maternal nest-building. In particular, $\sim 20 \%$ of mPOA neurons recorded in the study were activated during pup retrieval while $\sim 5 \%$ were activated during maternal nest-building. Fur- 
A

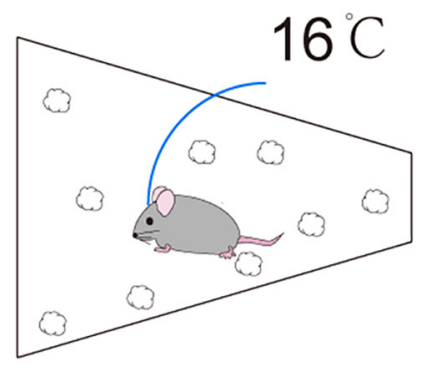

B

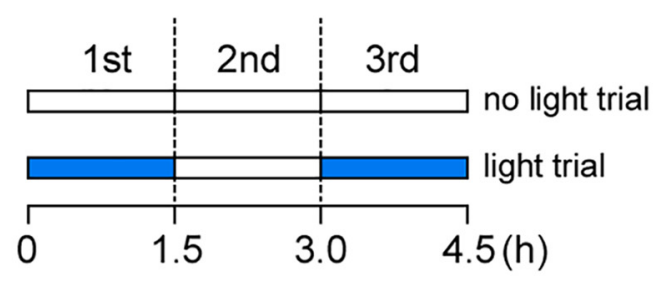

C

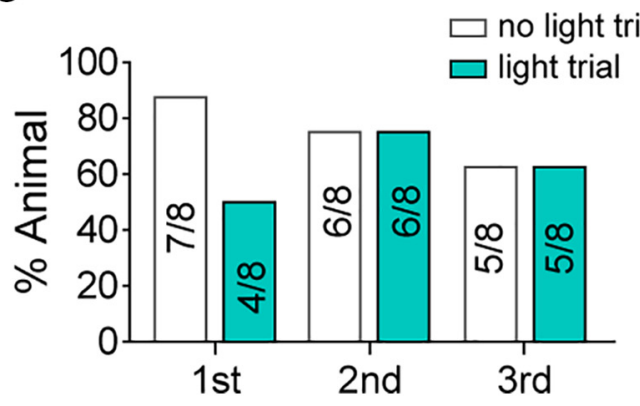

D

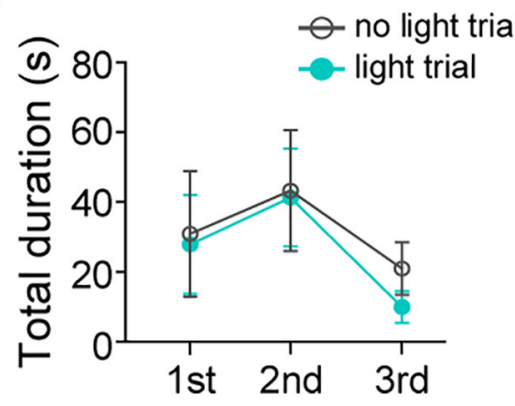

Figure 7. Nest-building induced by thermal challenge was not affected by optogenetic stimulation of AGRP $\rightarrow$ mPOA projections. $A$, AGRP ChR2 virgin females implanted with bilateral fibers into the mP0A were exposed to $16^{\circ} \mathrm{C}$ air temperature for $4.5 \mathrm{~h}$ with scattered nest material in the cage and monitored for nest-building behavior. $\boldsymbol{B}$, Light stimulation pattern. In "no light" trial, the external optic fiber was attached without the laser turned on. In "light" trial, laser was turned on during the "first" and "third" $1.5 \mathrm{~h}$ segment. Each animal was tested once in either condition. $\boldsymbol{C}, \boldsymbol{D}$, The percentage of animals (\%Animal) that displayed nest-building $(\boldsymbol{C})$ and the total duration, presented as mean \pm SEM, devoted to this behavior in $1.5 \mathrm{~h}(\boldsymbol{D})$ was not affected by light stimulation. $N=8$.

thermore, Esr1+ neurons were only activated during pup directed behaviors. Together, these results suggest that distinctive subsets of mPOA Vgat + neurons likely underlie pup retrieval and maternal nest-building.

To test whether activities in mPOA Vgat + neurons are in fact required for pup retrieval and maternal nest-building, we optogenetically inhibited these neurons by injecting AAVs encoding Cre-dependent GtACR1(Govorunova et al., 2015), a light gated chloride channel, bilaterally into the mPOA of Vgat-Ires-Cre females (Fig. 8D). Post hoc analysis revealed that expression of GtACR1 was mostly restricted to the mPOA (Fig. $8 E$ ) with an estimated spread of $\sim 747 \pm 33 \mu \mathrm{m}$ along the anterior-posterior axis and an infection rate of $\sim 28 \pm 2 \%$ of Nissl+ cells in the targeted region $(N=3)$. Control animals were injected with AAVs encoding Cre-dependent EYFP. GtACR1 mediated neuronal inhibition has the advantage of subsecond precision (Fig. $8 F$ ) compared with HM4D ( minutes to hours) and the advantage of reversibility compared with neuronal ablation and is therefore presumed to be more specific and less subjected to compensatory mechanisms or desensitization issues in vivo.

GtACR1 and control EYFP females were mated to produce pups and were subsequently tested during lactation or postpartum. Optogenetic inhibition of mPOA Vgat+ neurons during pup approaching greatly reduced the occurrence of pup retrieval behavior and the number of pups that was retrieved to the nest without affecting pup contact behaviors (paired two-tailed $t$ test; pup contact, EYFP, $0 \mathrm{~mW} 18.5 \pm 6.75 \mathrm{vs} 12 \mathrm{~mW} 13.33 \pm 2.80, t=$ $1.246, \mathrm{df}=2, p=0.3389, \mathrm{GtACR} 1,0 \mathrm{~mW} 10.5 \pm 3.78 \mathrm{vs} 12 \mathrm{~mW}$ $12.63 \pm 2.01, t=0.419, \mathrm{df}=3, p=0.703$; Fig. $8 G$; pup retrieval, \%trail, EYFP $0 \mathrm{~mW} 100 \%$ vs $12 \mathrm{~mW} 100 \%$, $p=1$, GtACR1, 0 $\mathrm{mW} 100 \%$ vs $12 \mathrm{~mW} 25 \pm 14.43 \%, t=5.196, \mathrm{df}=3, p=0.0138$, \#pups retrieved, EYFP, $0 \mathrm{~mW} 2.67 \pm 0.33$ vs $12 \mathrm{~mW} 2.83 \pm 0.17$, $t=1, \mathrm{df}=2, p=0.423, \mathrm{GtACR} 1,0 \mathrm{~mW} 2.38 \pm 0.38$ vs $12 \mathrm{~mW}$ $0.13 \pm 0.13, t=6.971, \mathrm{df}=3, p=0.0061$; Fig. $8 H$; EYFP, $N=3$, GtACR1, $N=4)$. Meanwhile, optogenetic inhibition of $\mathrm{mPOA}$ Vgat + neurons after a pup retrieval had already been initiated greatly reduced the likelihood that the carried pup was brought to the nest (EYFP $N=3,95.24 \pm 4.76 \%$, GtACR1, $N=4,31.8 \pm$ $8.09 \%$, unpaired two-tailed $t$ test, $t=6.116$, df $=5, p=0.0017$; Fig. $8 I$ ) without changing the average duration of the carry (EYFP, $N=3,2.81 \pm 1.59 \mathrm{~s}$, GtACR $1, N=5,2.56 \pm 0.46 \mathrm{~s}$, unpaired two-tailed $t$ test, $t=0.226, \mathrm{df}=6, p=0.83$ ). Not surprisingly, similar behavioral deficits in pup retrieval were also observed with optogenetic inhibition of mPOA Esr1+ neurons (Wei et al., 2018). More importantly, optogenetic inhibition of mPOA Vgat + neurons during maternal nest-building also interrupted the behavior as evidenced by reduced time that animals spent building the nest after light delivery, decreased mean duration of the nest-building bout and a shortened latency to terminate the behavior in GtACR1 animals compared with controls (EYFP, $N=5$, GtACR1, $N=6$, unpaired two-tailed $t$ test, mean duration, EYFP $4.48 \pm 0.75 \mathrm{~s}$ vs GtACR1 $2.60 \pm 0.26 \mathrm{~s}, t=2.551$, $\mathrm{df}=9, p=0.0312$, latency to stop, EYFP $4.94 \pm 0.60 \mathrm{~s}$ vs GtACR1 $1.76 \pm 0.51 \mathrm{~s}, t=4.051, \mathrm{df}=9, p=0.0029$; Fig. $8 \mathrm{~J})$, indicating that activities in mPOA Vgat + neurons are indeed required to maintain maternal nest-building. Together, we suggest that optogenetic stimulation of AGRP terminals in the mPOA selectively interfere with maternal nest-building perhaps by more prominently affecting neural subsets and/or activities that are associated with maternal nest-building.

\section{Discussion}

In order for animals to initiate ethologically appropriate behaviors, they must typically decide between behavioral repertoires 
A

$473 \mathrm{~nm}, 12 \mathrm{~mW}, 10 \mathrm{~ms}, 40 \mathrm{~Hz}, 15 \mathrm{~s}$

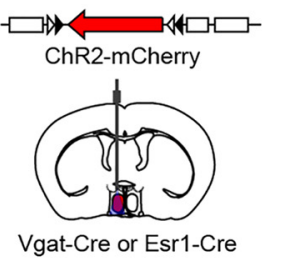

D

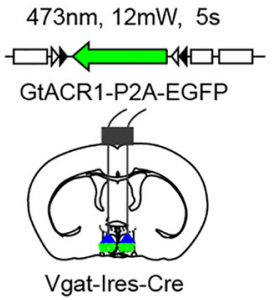

G
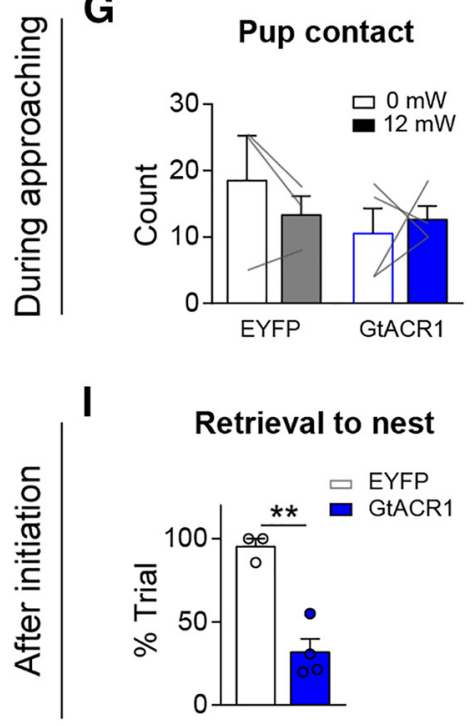

B

Pup retrieval

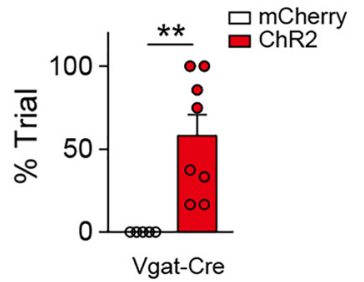

E

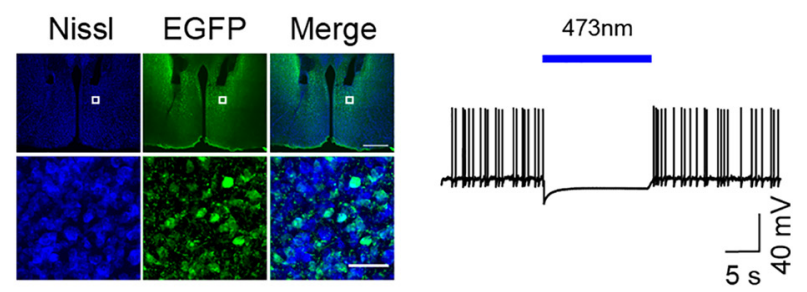

Nest building

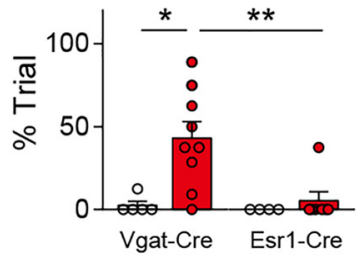

$\mathbf{F}$

H

Pup retrieval
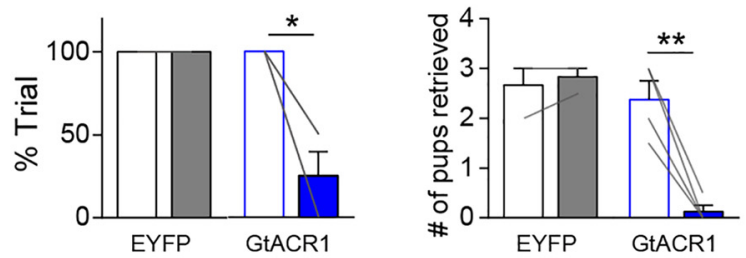

J

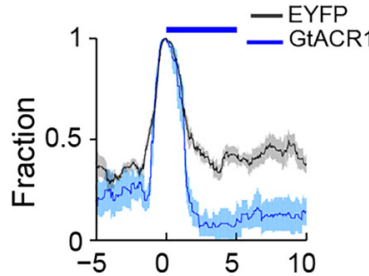

Nest building
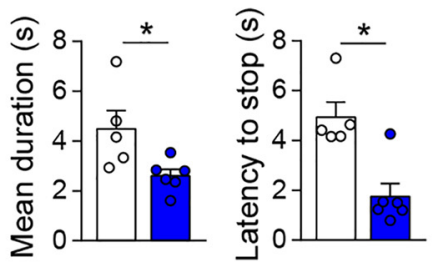

Figure 8. Distinctive subsets of $\mathrm{mPOA}$ Vgat + neurons likely underlie pup retrieval and maternal nest-building. $\boldsymbol{A}, \mathrm{AAVs}$ encoding Cre-inducible ChR2 fused with mCherry were injected unilaterally into the mPOA of Vgat-Cre or Esr1-Cre females and optic fibers were implanted. Stimulation were performed with $473 \mathrm{~nm}$ laser at $12 \mathrm{~mW}, 10 \mathrm{~ms}$ pulse, $40 \mathrm{~Hz}, 15 \mathrm{sper}$ bout. $\boldsymbol{B}, 0 \mathrm{ptogenetic}$ stimulation of $\mathrm{mPOA}$ Vgat + neurons elicited pup retrieval behavior after light delivery. \%Trial denotes the percentage of stimulation bouts that resulted in a pup retrieval behavior in each animal. $N=8$ ChR2 and 5 mCherry females. C, Optogenetic stimulation of mP0A Vgat + but not Esr1+ neurons elicited nest-building behavior after light delivery. \%Trial denotes the percentage of stimulation bouts that resulted in a nest-building behavior in each animal. $N=9$ ChR2 and 5 mCherry females for Vgat-Cre, and 7 ChR2 and 4 mCherry females for Esr1-Cre. D, AAVs encoding Cre-inducible GtACR1 linked to EYFP via a 2A cassette were injected bilaterally into the mPOA of Vgat-Ires-Cre and optic fibers were implanted. $\boldsymbol{E}$, Representative images showing expression of GtACR1 as indicated by EGFP immunostaining in the mPOA. Scale bars: top, $500 \mu \mathrm{m}$; bottom, $50 \mu \mathrm{m}$. F, Electrophysiological recordings of GtACR1-expressing neurons. Action potentials induced by withholding the membrane at a depolarizing potential with current injection were blocked under continuous blue light stimulation. $\mathbf{G}, \boldsymbol{H}$, Light was triggered and continuously delivered when animals entered and stayed in a prespecified area around each pup. Light stimulation did not affect count of pup contact behaviors ( $G$ ) but decreased the occurrence of pup retrieval behavior and the number of pups that were retrieved in GtACR1 females but not controls $(\boldsymbol{H}) . N=3 \mathrm{EYFP}$ and $4 \mathrm{GtACR} 1 . \boldsymbol{I}, \boldsymbol{J}$, Light was manually triggered and a $5 \mathrm{~s}$ light stimulation was delivered after the initiation of pup retrieval $(\boldsymbol{I})$ or nest-building $(\boldsymbol{J})$. Light stimulation resulted in decreased likelihood that a pup was retrieved to the nest in GtACR1 group compared with the control $(\boldsymbol{I})$. $N=3 \mathrm{EYFP}$ and 4 GtACR1. Light stimulation decreased the faction of time that females engaged in nest-building, the mean duration of nest-building and the latency to stop in GtACR1 females compared with the control $(\boldsymbol{J}) . N=5$ EYFP and $6 \mathrm{GtACR} 1$. Each gray line indicates paired value from an individual animal. Each circle represents an animal. All values are presented as mean \pm SEM. ${ }^{*} p<0.05 ;{ }^{* *} p<0.01$.

driven by multiple and often conflicting internal states. Despite recent progress on neural substrates that regulate individual behaviors (Wu et al., 2012; Allen et al., 2017; Andermann and Lowell, 2017; Chung et al., 2017; Mu et al., 2017; Sternson and Eiselt, 2017; Zhao et al., 2017; Augustine et al., 2018; Campos et al., 2018 , etc.), how these neural pathways interact to coherently and optimally modulate behavioral outputs, in particular to achieve a balance between behaviors that serve immediate physiological needs versus those that benefit the propagation of the species, remains largely unclear. Here, we characterized a direct pathway from AGRP neurons, a neuronal population known to drive hunger behaviors, to the $\mathrm{MPOA}$, a brain region critical for maternal care. We show that activation of AGRP neurons or AGRP $\rightarrow$ mPOA projections in females dramatically inhibits maternal 


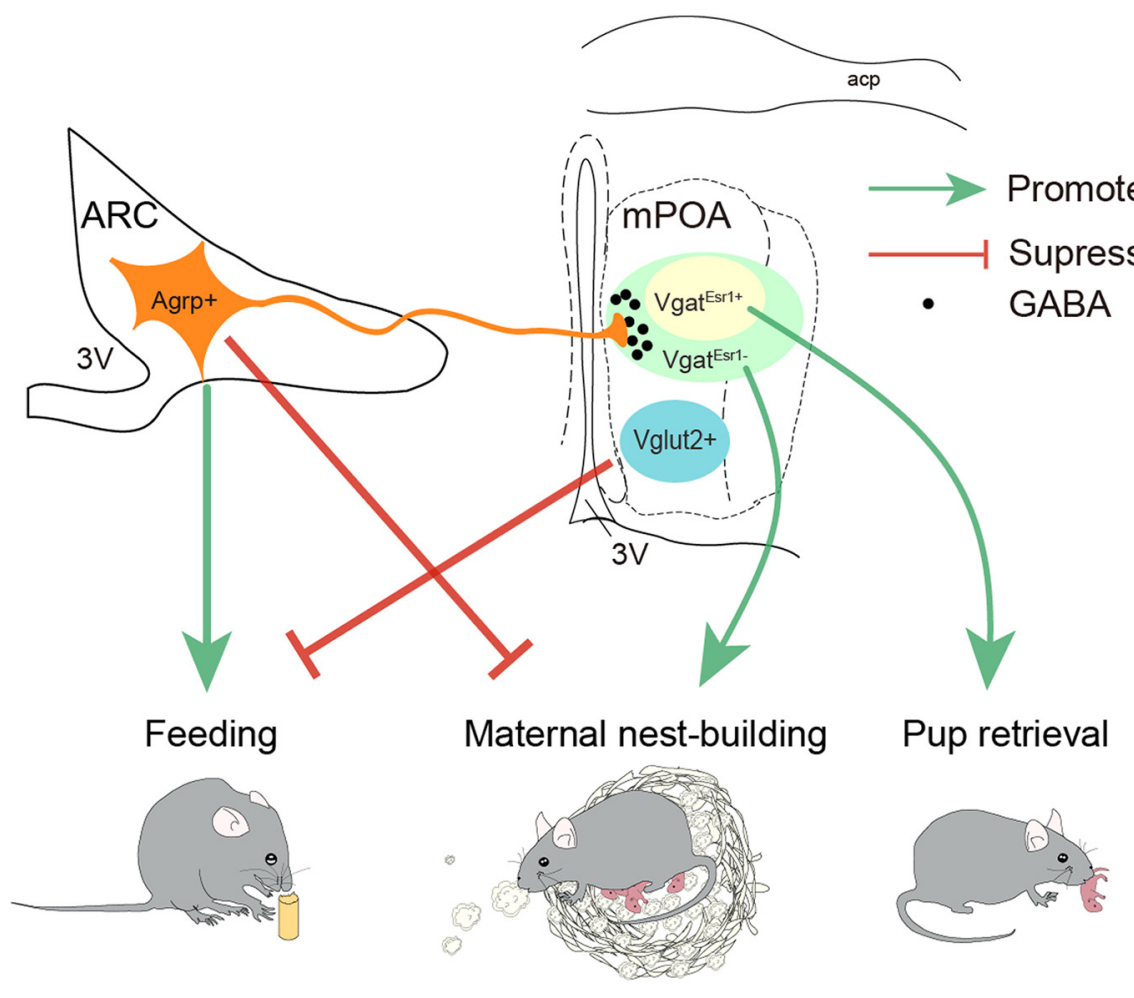

Figure 9. A model on reciprocal antagonisms between hunger and maternal care. AGRP neurons promote feeding; mPOA Vgat ${ }^{\text {Esr1 }}$ neurons promote pup retrieval and Vgat ${ }^{\text {Esr1- }}$ neurons are more important for maternal nest-building. Activation of AGRP neurons during hunger results in elevated inhibition of mPOA Vgat + neurons and suppression of maternal nest-building but not pup retrieval while in parallel activation of $\mathrm{mPOA}$ Vglut2 + neurons by pup derived cues delays and inhibits feedings. 3V, Third ventricle; acp, anterior commissure, posterior.

nest-building while leaving mostly intact pup retrieval behavior, demonstrating a previously unappreciated potential for AGRP neurons to directly modulate maternal care.

One caveat of our study is that despite extensive experimental efforts we could not provide explicit evidence that AGRP neurons projecting to the $\mathrm{MPOA}$ are activated during hunger, because of difficulties of retrograde viral tracing methods to label such a subset of AGRP neurons and sensitivity issues in terminal recordings of $\mathrm{Ca}^{2+}$ transients. This caveat highlights current technical challenges to study projections of moderate density in deep brain tissues. The only study (Betley et al., 2015) that has achieved long term in vivo recording of activities of individual AGRP neurons reports that 54 of 61 identified AGRP neurons show elevated GCamp6 signals after FD, demonstrating that the vast majority of AGRP neurons are activated during hunger. In addition, the stimulation parameter that we used in this study has been shown to promote a level of neuronal activation that is similar to that after $\sim 24$ h of FD (Mandelblat-Cerf et al., 2015; Jikomes et al., 2016). Furthermore, photostimulation of AGRP neurons or AGRP terminals mimic the effects of acute FD on the maternal nest-building, suggesting that activation of AGRP neurons likely mediate some effects of hunger on maternal care. The reason that the moderate inhibitory effects of hunger on pup retrieval cannot be recapitulated by optogenetic activation of AGRP neurons or terminals could be because of activation of other neural or endocrine systems along with AGRP neurons during starvation.

Interestingly, in both hunger and optogenetic stimulation of AGRP neurons/terminals pup retrieval is affected to a lesser extent than maternal nest-building. What might be the neural mechanisms that allow pup retrieval and maternal nest-building to be differentially modulated, given that the mPOA critically regulates both (Jacobson et al., 1980; Tsuneoka et al., 2013)? A recent study shows that pup retrieval and maternal nest-building are associated with different neuronal activity patterns in the MPOA and neurons that are activated during pup retrieval tends to be inhibited during nest-building (Fang et al., 2018). Correspondingly, we show that optogenetic activation of mPOA Vgat+ neurons elicits both pup retrieval and nest-building while stimulation of $\mathrm{mPOA}$ Esr $1+$ neurons, which account for $~ 50 \%$ of Vgat+ neurons, elicits only pup retrieval. Therefore, although the mPOA as a whole regulates both pup retrieval and maternal nest-building, distinct neuronal subsets likely underlie either behavior. Consistently, lesion or optogenetic inhibition of mPOA Vgat + neurons disrupt both pup retrieval and maternal nestbuilding. One discrepancy here is that chemogenetic inhibition of mPOA Vgat+ neurons only suppressed maternal nestbuilding in our study (Fig. 5). This discrepancy may be caused by the low infection rate of the HM4D virus $(\sim 20 \pm$ $2 \%$ of mPOA Nissl+ cells) compared with those achieved in optogenetic inhibition experiments $(\sim 28 \pm 2 \%$ of $\mathrm{mPOA}$ Nissl+ cells) or ablation experiments $(\sim 80 \%$ of mPOA Vgat+ neurons; Wei et al., 2018). It could also be because of incomplete neuronal suppression in HM4D experiments compared with optogenetic inhibition or ablation experiments. Regardless, we suggest that AGRP neurons may preferentially inhibit mPOA neurons underlying maternal nest-building thereby rendering maternal nestbuilding more sensitive to hunger modulation.

Noteworthy, heterogeneity of mPOA neurons in terms of genetic marker expression, projection patterns and behavioral functions have been extensively demonstrated (Tsuneoka et al., 2013, 2017; Wu et al., 2014; Kohl et al., 2018; Moffitt et al., 2018). For example, mPOA neurons that express the neuropeptide Galanin can be further divided to several different subpopulations and promote pup grooming via projections to different downstream targets, each of which mediates a distinctive motor or motivational aspect of the behavior (Kohl et al., 2018; Moffitt et al., 2018). Intriguingly, the arcuate nucleus provides a large fraction of inputs to mPOA Galanin + neurons and ablation of mPOA Galanin + neurons also results in decreased maternal nestbuilding (Wu et al., 2014; Kohl et al., 2018). It is attempting to speculate that perhaps a subset of mPOA Galanin + neurons regulate maternal nest-building, a possibility that remains to be tested experimentally. In general, better understanding of mPOA neuronal types through gene expression profiling at single-cell resolution coupled with functional investigation is needed to further deconvolute the diverse roles that the mPOA plays in maternal care and other behaviors (C. Li et al., 2018; Moffitt et al., 2018; Wei et al., 2018).

Finally, what might be the ethological significance to selectively reduce maternal nest-building but not pup retrieval? Mammalian pups depend on care provided by others to survive. 
Ethologically, retrieving pups that have wandered away from the nest protect pups from predation while building/maintaining a secure nest protect pups from coldness, hence both behaviors increase the survival rate of the young. Indeed, higher levels of maternal nest-building were positively linked to more and betterhealth offspring being produced in house mice over a long period of time (Bult and Lynch, 1997). Even so, one can imagine that in the wild retrieval of pups that have wondered away may be more pressing, failure of which more likely result in immediate loss of pups, therefore may be of higher priority to a female, even during hunger. Consistent with this view, we have previously found that presence of pups strongly delayed and decreased food consumption in virgin female mice and even suppressed feeding induced by optogenetic activation of AGRP neurons (Han et al., 2017). Moreover, chemogenetic activation of mPOA Vglut2+ but not Vgat + neurons were sufficient to suppress hunger-induced feeding (Han et al., 2017). Together with data presented here, we propose a model (Fig. 9) where during hunger activation of AGRP neurons results in elevated inhibition of mPOA Vgat+ neurons and suppression of maternal nest-building, whereas in parallel activation of mPOA Vglut2 + neurons and other brain regions by pup-derived sensory cues delays feedings. Such reciprocal antagonism allows a female to balance feeding with different components of maternal care, possibly to maximize fitness. In summary, our results offer new insight into neural organization of behaviors and neural mechanisms that coordinate behavioral selection.

\section{References}

Alhadeff AL, Su Z, Hernandez E, Klima ML, Phillips SZ, Holland RA, Guo C, Hantman AW, De Jonghe BC, Betley JN (2018) A neural circuit for the suppression of pain by a competing need state. Cell 173:140-152.e15. CrossRef Medline

Allen WE, DeNardo LA, Chen MZ, Liu CD, Loh KM, Fenno LE, Ramakrishnan C, Deisseroth K, Luo L (2017) Thirst-associated preoptic neurons encode an aversive motivational drive. Science 357:1149-1155. CrossRef Medline

Andermann ML, Lowell BB (2017) Toward a wiring diagram understanding of appetite control. Neuron 95:757-778. CrossRef Medline

Aponte Y, Atasoy D, Sternson SM (2011) AGRP neurons are sufficient to orchestrate feeding behavior rapidly and without training. Nat Neurosci 14:351-355. CrossRef Medline

Atasoy D, Betley JN, Su HH, Sternson SM (2012) Deconstruction of a neural circuit for hunger. Nature 488:172-177. CrossRef Medline

Augustine V, Gokce SK, Lee S, Wang B, Davidson TJ, Reimann F, Gribble F, Deisseroth K, Lois C, Oka Y (2018) Hierarchical neural architecture underlying thirst regulation. Nature 555:204-209. CrossRef Medline

Betley JN, Cao ZF, Ritola KD, Sternson SM (2013) Parallel, redundant circuit organization for homeostatic control of feeding behavior. Cell 155: 1337-1350. CrossRef Medline

Betley JN, Xu S, Cao ZFH, Gong R, Magnus CJ, Yu Y, Sternson SM (2015) Neurons for hunger and thirst transmit a negative-valence teaching signal. Nature 521:180-185. CrossRef Medline

Beutler LR, Chen Y, Ahn JS, Lin YC, Essner RA, Knight ZA (2017) Dynamics of gut-brain communication underlying hunger. Neuron 96:461-475.e5. CrossRef Medline

Bridges RS (1975) Long-term effects of pregnancy and parturition upon maternal responsiveness in the rat. Physiol Behav 14:245-249. CrossRef Medline

Broberger C, Johansen J, Johansson C, Schalling M, Hökfelt T (1998) The neuropeptide Y/agouti gene-related protein (AGRP) brain circuitry in normal, anorectic, and monosodium glutamate-treated mice. Proc Natl Acad Sci U S A 95:15043-15048. CrossRef Medline

Bult A, Lynch CB (1997) Nesting and fitness: lifetime reproductive success in house mice bidirectionally selected for thermoregulatory nest-building behavior. Behav Genet 27:231-240. CrossRef Medline

Burnett CJ, Li C, Webber E, Tsaousidou E, Xue SY, Brüning JC, Krashes MJ
(2016) Hunger-driven motivational state competition. Neuron 92:187201. CrossRef Medline

Campos CA, Bowen AJ, Roman CW, Palmiter RD (2018) Encoding of danger by parabrachial CGRP neurons. Nature 555:617-622. CrossRef Medline

Carter ME, Soden ME, Zweifel LS, Palmiter RD (2013) Genetic identification of a neural circuit that suppresses appetite. Nature 503:111-114. CrossRef Medline

Chao HT, Chen H, Samaco RC, Xue M, Chahrour M, Yoo J, Neul JL, Gong S, Lu HC, Heintz N, Ekker M, Rubenstein JL, Noebels JL, Rosenmund C, Zoghbi HY (2010) Dysfunction in GABA signalling mediates autismlike stereotypies and rett syndrome phenotypes. Nature 468:263-269. CrossRef Medline

Chen Y, Lin YC, Kuo TW, Knight ZA (2015) Sensory detection of food rapidly modulates arcuate feeding circuits. Cell 160:829-841. CrossRef Medline

Chung S, Weber F, Zhong P, Tan CL, Nguyen TN, Beier KT, Hörmann N, Chang WC, Zhang Z, Do JP, Yao S, Krashes MJ, Tasic B, Cetin A, Zeng H, Knight ZA, Luo L, Dan Y (2017) Identification of preoptic sleep neurons using retrograde labelling and gene profiling. Nature 545:477-481. CrossRef Medline

Cowley MA, Smith RG, Diano S, Tschöp M, Pronchuk N, Grove KL, Strasburger CJ, Bidlingmaier M, Esterman M, Heiman ML, Garcia-Segura LM, Nillni EA, Mendez P, Low MJ, Sotonyi P, Friedman JM, Liu H, Pinto S, Colmers WF, Cone RD, et al. (2003) The distribution and mechanism of action of ghrelin in the CNS demonstrates a novel hypothalamic circuit regulating energy homeostasis. Neuron 37:649-661. CrossRef Medline

Cowley MA, Smart JL, Rubinstein M, Cerdán MG, Diano S, Horvath TL, Cone RD, Low MJ (2001) Leptin activates anorexigenic POMC neurons through a neural network in the arcuate nucleus. Nature 411:480-484. CrossRef Medline

Dulac C, O'Connell LA, Wu Z (2014) Neural control of maternal and paternal behaviors. Science 345:765-770. CrossRef Medline

Fang YY, Yamaguchi T, Song SC, Tritsch NX, Lin D (2018) A hypothalamic midbrain pathway essential for driving maternal behaviors. Neuron 98 : 192-207.e10. CrossRef Medline

Govorunova EG, Sineshchekov OA, Janz R, Liu X, Spudich JL (2015) NEUROSCIENCE. natural light-gated anion channels: a family of microbial rhodopsins for advanced optogenetics. Science 349:647-650. CrossRef Medline

Hahn TM, Breininger JF, Baskin DG, Schwartz MW (1998) Coexpression of agrp and NPY in fasting-activated hypothalamic neurons. Nat Neurosci 1:271-272. CrossRef Medline

Han Y, Li XY, Wang SR, Wei YC, Xu XH (2017) Presence of pups suppresses hunger-induced feeding in virgin adult mice of both sexes. Neuroscience 362:228-238. CrossRef Medline

Jacobson CD, Terkel J, Gorski RA, Sawyer CH (1980) Effects of small medial preoptic area lesions on maternal behavior: retrieving and nest building in the rat. Brain Res 194:471-478. CrossRef Medline

Jennings JH, Rizzi G, Stamatakis AM, Ung RL, Stuber GD (2013) The inhibitory circuit architecture of the lateral hypothalamus orchestrates feeding. Science 341:1517-1521. CrossRef Medline

Jikomes N, Ramesh RN, Mandelblat-Cerf Y, Andermann ML (2016) Preemptive stimulation of AgRP neurons in fed mice enables conditioned food seeking under threat. Curr Biol CB 26:2500-2507. CrossRef Medline

Kamegai J, Tamura H, Shimizu T, Ishii S, Sugihara H, Wakabayashi I (2000) Central effect of ghrelin, an endogenous growth hormone secretagogue, on hypothalamic peptide gene expression. Endocrinology 141:47974800. CrossRef Medline

Kohl J, Babayan BM, Rubinstein ND, Autry AE, Marin-Rodriguez B, Kapoor V, Miyamishi K, Zweifel LS, Luo L, Uchida N, Dulac C (2018) Functional circuit architecture underlying parental behaviour. Nature 556: 326-331. CrossRef Medline

Krashes MJ, Koda S, Ye C, Rogan SC, Adams AC, Cusher DS, Maratos-Flier E, Roth BL, Lowell BB (2011) Rapid, reversible activation of AgRP neurons drives feeding behavior in mice. J Clin Invest 121:1424-1428. CrossRef Medline

Krashes MJ, Shah BP, Koda S, Lowell BB (2013) Rapid versus delayed stimulation of feeding by the endogenously released AgRP neuron mediators GABA, NPY, and AgRP. Cell Metab 18:588-595. CrossRef Medline

Kuroda KO, Numan M (2014) The medial preoptic area and the regulation of parental behavior. Neurosci Bull 30:863-865. CrossRef Medline 
Li C, Wang S, Chen Y, Zhang X (2018) Somatosensory neuron typing with high-coverage single-cell RNA sequencing and functional analysis. Neurosci Bull 34:200-207. CrossRef Medline

Li Y, Zeng J, Zhang J, Yue C, Zhong W, Liu Z, Feng Q, Luo M (2018) Hypothalamic circuits for predation and evasion. Neuron 97:911-924.e5. CrossRef Medline

Livneh Y, Ramesh RN, Burgess CR, Levandowski KM, Madara JC, Fenselau H, Goldey GJ, Diaz VE, Jikomes N, Resch JM, Lowell BB, Andermann ML (2017) Homeostatic circuits selectively gate food cue responses in insular cortex. Nature 546:611-616. CrossRef Medline

Luquet S, Perez FA, Hnasko TS, Palmiter RD (2005) NPY/AgRP neurons are essential for feeding in adult mice but can be ablated in neonates. Science 310:683-685. CrossRef Medline

Madisen L, Mao T, Koch H, Zhuo JM, Berenyi A, Fujisawa S, Hsu YW, Garcia AJ 3rd, Gu X, Zanella S, Kidney J, Gu H, Mao Y, Hooks BM, Boyden ES, Buzsáki G, Ramirez JM, Jones AR, Svoboda K, Han X, et al. (2012) A toolbox of Cre-dependent optogenetic transgenic mice for light-induced activation and silencing. Nat Neurosci 15:793-802. CrossRef Medline

Mandelblat-Cerf Y, Ramesh RN, Burgess CR, Patella P, Yang Z, Lowell BB, Andermann ML (2015) Arcuate hypothalamic AgRP and putative POMC neurons show opposite changes in spiking across multiple timescales. eLife 4:e07122 . CrossRef Medline

Moffitt JR, Bambah-Mukku D, Eichhorn SW, Vaughn E, Shekhar K, Perez JD, Rubinstein ND, Hao J, Regev A, Dulac C, Zhuang X (2018) Molecular, spatial and functional single-cell profiling of the hypothalamic preoptic region. Science 362:eaau5324. CrossRef Medline

Mu D, Deng J, Liu KF, Wu ZY, Shi YF, Guo WM, Mao QQ, Liu XJ, Li H, Sun YG (2017) A central neural circuit for itch sensation. Science 357:695699. CrossRef Medline

Newman SW (1999) The medial extended amygdala in male reproductive behavior. A node in the mammalian social behavior network. Ann N Y Acad Sci 877:242-257. CrossRef Medline

Numan M (1974) Medial preoptic area and maternal behavior in the female rat. J Comp Physiol Psychol 87:746-759. CrossRef Medline

Padilla SL, Qiu J, Soden ME, Sanz E, Nestor CC, Barker FD, Quintana A, Zweifel LS, Rønnekleiv OK, Kelly MJ, Palmiter RD (2016) Agoutirelated peptide neural circuits mediate adaptive behaviors in the starved state. Nat Neurosci 19:734-741. CrossRef Medline

Padilla SL, Qiu J, Nestor CC, Zhang C, Smith AW, Whiddon BB, Rønnekleiv OK, Kelly MJ, Palmiter RD (2017) AgRP to Kiss1 neuron signaling links nutritional state and fertility. Proc Natl Acad Sci U S A 114:2413-2418. CrossRef Medline

Palou M, Sánchez J, Rodríguez AM, Priego T, Picó C, Palou A (2009) Induction of NPY/AgRP orexigenic peptide expression in rat hypothalamus is an early event in fasting: relationship with circulating leptin, insulin and glucose. Cell Physiol Biochem 23:115-124. CrossRef Medline

Petreanu L, Huber D, Sobczyk A, Svoboda K (2007) Channelrhodopsin-2assisted circuit mapping of long-range callosal projections. Nat Neurosci 10:663-668. CrossRef Medline

Pfeffer CK, Xue M, He M, Huang ZJ, Scanziani M (2013) Inhibition of inhibition in visual cortex: the logic of connections between molecularly distinct interneurons. Nat Neurosci 16:1068-1076. CrossRef Medline

Pinto S, Roseberry AG, Liu H, Diano S, Shanabrough M, Cai X, Friedman JM,
Horvath TL (2004) Rapid rewiring of arcuate nucleus feeding circuits by leptin. Science 304:110-115. CrossRef Medline

Scott N, Prigge M, Yizhar O, Kimchi T (2015) A sexually dimorphic hypothalamic circuit controls maternal care and oxytocin secretion. Nature 525:519-522. CrossRef Medline

Sternson SM, Eiselt AK (2017) Three pillars for the neural control of appetite. Annu Rev Physiol 79:401-423. CrossRef Medline

Su Z, Alhadeff AL, Betley JN (2017) Nutritive, post-ingestive signals are the primary regulators of AgRP neuron activity. Cell Rep 21:2724-2736. CrossRef Medline

Tan CL, Cooke EK, Leib DE, Lin YC, Daly GE, Zimmerman CA, Knight ZA (2016) Warm-sensitive neurons that control body temperature. Cell 167: 47-59.e15. CrossRef Medline

Tsuneoka Y, Maruyama T, Yoshida S, Nishimori K, Kato T, Numan M, Kuroda KO (2013) Functional, anatomical, and neurochemical differentiation of medial preoptic area subregions in relation to maternal behavior in the mouse. J Comp Neurol 521:1633-1663. CrossRef Medline

Tsuneoka Y, Yoshida S, Takase K, Oda S, Kuroda M, Funato H (2017) Neurotransmitters and neuropeptides in gonadal steroid receptor-expressing cells in medial preoptic area subregions of the male mouse. Sci Rep 7:9809. CrossRef Medline

Valtorta F, Pennuto M, Bonanomi D, Benfenati F (2004) Synaptophysin: leading actor or walk-on role in synaptic vesicle exocytosis? Bioessays 26:445-453. CrossRef Medline

Varela L, Horvath TL (2012) Leptin and insulin pathways in POMC and AgRP neurons that modulate energy balance and glucose homeostasis. EMBO Rep 13:1079-1086. CrossRef Medline

Wei YC, Wang SR, Jiao ZL, Zhang W, Lin JK, Li XY, Li SS, Zhang X, Xu XH (2018) Medial preoptic area in mice is capable of mediating sexually dimorphic behaviors regardless of gender. Nat Commun 9:279. CrossRef Medline

Wu Q, Boyle MP, Palmiter RD (2009) Loss of GABAergic signaling by AgRP neurons to the parabrachial nucleus leads to starvation. Cell 137:12251234. CrossRef Medline

Wu Q, Clark MS, Palmiter RD (2012) Deciphering a neuronal circuit that mediates appetite. Nature 483:594-597. CrossRef Medline

Wu Z, Autry AE, Bergan JF, Watabe-Uchida M, Dulac CG (2014) Galanin neurons in the medial preoptic area govern parental behaviour. Nature 509:325-330. CrossRef Medline

Xu W, Südhof TC (2013) A neural circuit for memory specificity and generalization. Science 339:1290-1295. CrossRef Medline

Xu X, Coats JK, Yang CF, Wang A, Ahmed OM, Alvarado M, Izumi T, Shah NM (2012) Modular genetic control of sexually dimorphic behaviors. Cell 148:596-607. CrossRef Medline

Yang CF, Shah NM (2014) Representing sex in the brain, one module at a time. Neuron 82:261-278. CrossRef Medline

Zha X, Xu X (2015) Dissecting the hypothalamic pathways that underlie innate behaviors. Neurosci Bull 31:629-648. CrossRef Medline

Zhao ZD, Yang WZ, Gao C, Fu X, Zhang W, Zhou Q, Chen W, Ni X, Lin JK, Yang J, Xu XH, Shen WL (2017) A hypothalamic circuit that controls body temperature. Proc Natl Acad Sci U S A 114:2042-2047. CrossRef Medline 